Fearless Dominance/Boldness is not strongly related to externalizing behaviors: An item

$$
\begin{aligned}
& \text { response-based analysis } \\
& \text { Michael L. Crowe } \\
& \text { University of Georgia } \\
& \text { Brandon M. Weiss } \\
& \text { University of Georgia } \\
& \text { Chelsea E. Sleep } \\
& \text { University of Georgia } \\
& \text { Alexandra M. Harris } \\
& \text { University of Georgia } \\
& \text { Nathan T. Carter } \\
& \text { University of Georgia } \\
& \text { Doshua D. Miller } \\
& \text { Purdue University }
\end{aligned}
$$

Correspondence concerning this article should be addressed to Michael L. Crowe or Joshua D. Miller, Department of Psychology, University of Georgia, Athens, GA 30602. Email: crowem@uga.edu; jdmiller@uga.edu. For access to data or other inquiries contact the first author.

Acknowledgements: Nathan T. Carter's contribution was supported by the National Science Foundation under Grant SES-1561070. Any opinions, findings, and conclusions expressed in this material are those of the authors and do not necessarily reflect the views of the National Science Foundation. 


\begin{abstract}
There is substantial and ongoing debate regarding the centrality of Fearless Dominance/Boldness (FD/B) to psychopathic personality due, in part, to its generally weak relations with externalizing behaviors. In response to these findings, proponents of FD/B have offered two hypotheses. First, FD/B may have non-linear associations with externalizing outcomes such that FD/B may lead to resilience at moderate levels, but an overabundance of FD/B will yield maladaptive behavioral outcomes. Second, FD/B may be related to antisocial outcomes when paired with high scores on other psychopathic traits such as self-centered impulsivity (SCI), meanness, or disinhibition. The current study tests these two possibilities using two large samples (Study 1: 787 undergraduates; Study 2: 596 MTurk participants). An Item-Response Theory (IRT) scoring approach particularly sensitive to curvilinearity was used to maximize our ability to find a true curvilinear effect, if present. No evidence in favor of the curvilinearity hypothesis was found. Only a single significant interaction predicting substance use was observed between boldness and meanness. These findings contribute to a growing literature raising concerns regarding the relevance of FD/B to psychopathy.
\end{abstract}

Keywords: Nonlinear, Curvilinearity, Antisocial PD, IRT 


\section{Fearless Dominance/Boldness is not strongly related to externalizing behaviors: An item}

\section{response-based analysis}

Psychopathy is one of the most commonly examined and well-validated personality disorder constructs. However, considerable debate remains regarding its underlying structure and the centrality of certain components (e.g., Lilienfeld et al., 2012; Lynam \& Miller, 2012; Miller \& Lynam, 2012). One of the most widely debated elements of psychopathy is Fearless Dominance (FD)/Boldness (B), which is characterized by resilience to stress and anxiety, fearlessness, and social influence. Formulations of the FD/B construct are represented in certain classic clinical descriptions of the disorder from the mid to late $20^{\text {th }}$ century, in which psychopathic individuals are described as at once callous, egocentric, impulsive, and irresponsible while also seemingly well-mannered, charming, and agentic (e.g., Cleckley, 1976; Miller, Lynam, Widiger, \& Leukefeld, 2001; Crego \& Widiger, 2016). However, FD/B traits do not figure as prominently in other modern conceptualizations of psychopathy such as Hare's model and measure, the Psychopathy Checklist (PCL; Hare, 1980; PCL-R; Hare, 2003), or its derivatives such as the Self-report Psychopathy Scale (Paulhus, Neumann, \& Hare, 2017) and Levenson Self-report Psychopathy Scale (Levenson, Kiehl, \& Fitzpatrick, 1995). These traits were excluded due to their lack of relations with other psychopathy-relevant traits and outcomes (Hare \& Neumann, 2008; Miller \& Lynam, 2012). For instance, a meta-analysis of the Psychopathic Personality Inventory (PPI; Lilienfeld \& Andrews, 1996) showed that FD manifested null to small positive relations with antisocial behaviors that some consider the sine qua non of psychopathy-related outcomes (Miller \& Lynam, 2012; cf., Skeem \& Cooke, 2010). A recent meta-analytic review of the Triarchic Psychopathy Measure (Patrick, 2010) revealed the same pattern for Boldness (Sleep, Weiss, Lynam, \& Miller, 2019). 
Two hypotheses for the importance of FD/B have been proposed. First, FD/B may have non-linear associations with externalizing outcomes such that FD/B may lead to resilience at moderate levels, but an overabundance of FD/B will yield maladaptive behavioral outcomes. Second, FD/B may be related to antisocial outcomes when paired with high scores on other psychopathic traits such as self-centered impulsivity (SCI), meanness, or disinhibition. The present study tests both hypotheses.

\section{Measures of Fearless Dominance/Boldness}

The Psychopathy Personality Inventory (PPI; Lilienfeld \& Andrews, 1996), as well as its subsequent revision, the PPI-Revised ${ }^{1}$ (PPI-R; Lilienfeld \& Widows, 2005), is a widely used measure that treats FD/B as a major factor of psychopathy. PPI-based measures contain eight subscales that can be grouped into two higher order factors titled Fearless Dominance (PPI FD comprising 3 subscales: Fearlessness, Stress Immunity, and Social Influence) and Self-centered Impulsivity (PPI SCI - comprising four subscales: Machiavellian Egocentricity, Rebellious Nonconformity, Blame Externalization, and Carefree Nonplanfulness). An eighth subscale Coldheartedness (PPI C) - is a separate scale that does not load on either of the two higher order factors.

More recent measures such as the Triarchic Psychopathy Measure (TriPM; Patrick, 2010) and the Elemental Psychopathy Assessment (EPA; Lynam et al., 2011) have followed suit in including an FD-like construct as a component of psychopathy. The TriPM is based on Patrick, Fowles, and Krueger's (2009) triarchic psychopathy model, which includes three central psychopathy traits - Boldness, Meanness, and Disinhibition. Empirically, TriPM Boldness overlaps very strongly with PPI FD (e.g., $r$ s >.80). In general, PPI FD and TriPM Boldness

\footnotetext{
${ }^{1}$ Referred to as the PPI in rest of manuscript for sake of parsimony.
} 
appear to measure the same construct as both are mutually characterized by resilience to fear and anxiety, social dominance, low neuroticism, and high extraversion (e.g., Patrick et al., 2009) and are very highly correlated (meta-analytic $r=.79$, Sleep et al., 2019).

\section{Controversy of Fearless Dominance/Boldness}

Although the PPI-R and TriPM are widely used (e.g., Ross, Benning, Patrick, Thompson, \& Thurston, 2009; Witt, Donnellan, \& Blonigen, 2009), empirical support for the FD/B construct is mixed, with a growing number of findings raising questions regarding FD/B's relevance to psychopathy. While some researchers have suggested that FD/B serves to assess psychopathic traits represented by Factor 1 of the PCL and its subsequent revision, the Psychopathy Checklist - Revised (PCL-R; Hare, 2003), they share only a small amount of variance. In fact, the variance shared between Factor 1 of the PCL-R and FD is smaller than that shared between Factor 1 and SCI (see Marcus, Fulton, \& Edens, 2012; Miller \& Lynam, 2012). Previous findings also indicate that FD/B bears null to weak positive relations with many other psychopathy measures and subscales, suggesting weaker convergent validity than other components of psychopathy (Miller \& Lynam, 2012; cf., Murphy, Lilienfeld, Skeem \& Edens, 2016). For example, PPI FD shows null to weak relations with the other higher order factor, PPI SCI, which is thought to assess core psychopathy traits (Crego \& Widiger, 2014; see Miller \& Lynam, 2012 for a metaanalysis); the same is true for TriPM Boldness and its relations with Meanness (meta-analytic $r=$ .16) and Disinhibition (meta-analytic $r=-.05$; Sleep et al., 2019). Such null findings run counter to theories that suggest low anxiety is the foundation of psychopathy (Lykken, 1995). They are, however, contrasted by the meta-analytic finding that PPI-FD has a moderate to strong association with Factors 1 and 2 of the SRP (Marcus et al., 2012). 
It is possible that previous meta-analyses on the relationship between FD/B and other components of psychopathy are misleading due to their reliance on the PCL-R, which puts little emphasis on boldness (Lilienfeld et al., 2016), although relations with other psychopathy measures are relatively small as well (Sleep et al., 2019). FD/B's relations with non-PCL-based measures of psychopathy are stronger - but the magnitude of those effects is quite variable.

Second, there is limited empirical evidence indicating that PPI FD and TriPM Boldness converge with other psychopathy scales in relation to important correlates of psychopathy. For instance, FD generally manifests null to small relations with externalizing behaviors thought by many, but not all (Skeem \& Cooke, 2010), to be characteristic of psychopathy such as aggression, substance use, and antisocial behavior (see Miller \& Lynam, 2012). Similar findings have been reported regarding TriPM Boldness; a recent meta-analysis found relations for Boldness with indices of externalizing behaviors to range from .05 to .12 (Sleep et al., 2019).

Third, previous findings indicate that $\mathrm{FD} / \mathrm{B}$ is more strongly related to adaptive outcomes than maladaptive ones. While the construct does show moderate convergence with an expertgenerated prototype of Cleckley-based psychopathy from the perspective of the Five Factor Model (Lilienfeld et al., 2012; Miller \& Lynam, 2012), it is associated with lower risk of psychopathology and greater emotional stability (e.g., Crego \& Widiger, 2014; Miller \& Lynam, 2012). FD/B is also strongly associated with low neuroticism/negative emotionality and high extraversion/positive emotionality, suggesting that it may be linked to such positive life outcomes as subjective well-being, self-esteem, physical health, and longevity, among others (Ozer \& Benet-Martinez, 2006). Smith, Lilienfeld, Coffey, and Dabbs (2013) have shown that FD/B traits are associated with acting heroically and altruistically in daily life - behaviors not typically associated with psychopathy. FD/B is also associated with qualities that underlie 
prosocial behavior including emotion recognition, empathy, and sociability, as well as prosocial behavior itself (Gatner et al., 2016). There is some evidence that FD/B is related to grandiose narcissism (e.g., Sellbom \& Phillips, 2013) but these shared aspects are largely limited to the more adaptive, extraversion-related components of narcissism that do not involve the interpersonal antagonism characteristic of psychopathy and narcissism (Krusemark, Campbell, Crowe, \& Miller, 2018; Miller, Sleep, Crowe, \& Lynam, 2020). This is consistent with narcissism and FD/B's shared association with FFM extraversion, but divergent association with agreeableness (e.g., Crego \& Widiger, 2014; Maples et al., 2014; O’Boyle, Forsyth, Banks, Story, \& White, 2015). Finally, when the personality profile associated with boldness is presented without any psychopathy-related labeling or context, experts rated it as less relevant to psychopathy than Meanness or Disinhibition (Miller, Lamkin, Maples-Keller, \& Lynam, 2016; cf., Berg, Lilienfeld, \& Sellbom, 2017). In fact, unlike other dimensions of psychopathy, the personality correlates of FD/B align strongly with expert ratings of "healthy personality" (Bleidorn et al., in press).

There have been several attempts to explain FD/B's null to limited relations with psychopathy-relevant outcomes such as antisocial behavior. The first is an interaction-based hypothesis that suggests that FD/B will be related to externalizing behaviors when paired with higher scores on other psychopathy components such as PPI SCI, meanness, or disinhibition. Lilienfeld and colleagues (2012) suggest that "fearless dominance...gives rise to the full clinical picture of psychopathy in the presence of elevated disinhibition, meanness, or both... there is no requirement that PPI-FD by itself should be associated with maladaptive functioning” (p. 332), although they note that these interactions have been difficult to detect (Lilienfeld et al., 2012). Empirical examinations of the interaction hypothesis have yielded mixed results, with a few 
studies noting FD x SCI interactions in relation to treatment failure (Rock, Sellbom, Ben-Porath, \& Salekin, 2013), and sexually predatory attitudes (Marcus \& Norris, 2014), while other studies have found no evidence of interactive effects (e.g., Gatner et al., 2016; Maples et al., 2014; Miller, Maples-Keller, \& Lynam, 2016; see Lilienfeld, Patrick, et al., 2012 for other examples). For example, across 42 outcomes, Vize et al. (2015) found evidence for only two FD by SCI interactions, and neither was in the anticipated direction. More recently, the interaction hypothesis was tested in a correctional sample (Weiss et al., 2019). Weiss and colleagues found no evidence of FD by SCI interactions for any of the four outcomes tested. Indeed, if FD/B interacts with the other components of psychopathy, some findings suggest that it may provide a protective effect. For instance, Gatner and colleagues' (2016) demonstrated that at higher levels of TriPM Boldness, (a) Disinhibition and Meanness failed to exhibit stronger relations with negative outcomes; (b) meanness exhibited weaker relations with social aggression and impulsiveness.

A second possible explanation for why examinations of $\mathrm{FD} / \mathrm{B}$ have failed to find expected relations with antisocial behavior and other externalizing behaviors was put forward by Blonigen (2013), who hypothesized that FD/B may bear curvilinear relations with maladaptive outcomes, such that optimal outcomes are shown in those with moderate standing on FD, whereas those with very high levels are disposed toward problematic behavior. Specifically, Blonigen (2013) stated:

[A] certain amount of boldness, fearlessness, confidence, and social dominance is likely to engender resilience in the face of adversity and success in a number of important life domains; however, an overabundance of such traits is likely to be expressed as narcissism, arrogance, recklessness, and risk-taking... (p. 88). 
Unlike the interaction-based explanation, this curvilinear hypothesis regarding FD/B's relations to externalizing behaviors has received little attention to date. Vize and colleagues (2016) tested the effect of $\mathrm{FD} / \mathrm{B}$ on both concurrent and future behavior, and found that $\mathrm{FD} / \mathrm{B}$, measured by proxy in early adolescents, showed a curvilinear effect for three of 42 possible outcomes; importantly, none of these curvilinear effects were of the same form and only one was consistent with Blonigen's hypothesis. Similarly, Gatner et al. (2016) tested TriPM Boldness' curvilinear relation with several antisocial criteria, finding that Boldness exhibited a small incremental nonlinear effect when predicting TriPM Meanness and physical aggression. The authors interpreted their effect sizes as too small in magnitude to support Blonigen's (2013) hypothesis. In general, these two studies cast doubt on the existence of important curvilinear relations among FD/B and externalizing outcomes, but both had limitations. First, a null finding in the Vize et al. study for curvilinear relations does not necessarily preclude the possibility that extreme levels of FD/B in adulthood (versus early life) predict antisocial behavior. Second, the use of a proxy measure of FD limited the authors' ability to test whether the lower-order components of FD (e.g., stress immunity) demonstrate curvilinear relations with externalizing behavior. Given the multi-faceted nature of FD, it is possible that curvilinear effects associated with lower order subcomponents may have been obscured in the higher-order analysis. Lastly, both simulated and traditional analyses have indicated that traditional scoring methods are limited in their ability to detect curvilinearity at extreme ends of trait distributions (Carter et al., 2014, 2016, 2017). More recently, Weiss and colleagues (in press) evaluated the curvilinearity hypothesis on a correctional sample, finding no support for the hypothesis, but their analysis was limited to the PPI.

\section{Study Aims}


In the present study, we test both key hypotheses regarding how FD/B may relate to externalizing outcomes. We specifically examine whether FD/B shows an increasingly strong positive association with externalizing at high ends of the $\mathrm{FD} / \mathrm{B}$ trait distribution (Blonigen, 2013), and whether FD/B interacts with high SCI, disinhibition, or meanness to predict externalizing behavior. We utilize the two most common measures of FD/B (i.e., PPI-R and TriPM) and test these hypotheses in a large undergraduate sample and a large Mechanical Turk sample, both of which are large enough to be reasonably well-powered for such analyses (see Results and Supplemental Power Analysis in supplemental materials for more details on the power analysis conducted). For the sake of comprehensiveness, we also test whether the nonFD/B related scales of the PPI-R and TriPM's (e.g., PPI-R Coldheartedness; TriPM Meanness) bear curvilinear relations with externalizing behaviors. By examining the subscales of the PPIR's FD factor we can conduct a more granular test of where curvilinear relations may exist within the broader construct.

To investigate curvilinearity, we use an ideal point Item Response Theory (IRT) model, namely, the Generalized Graded Unfolding Model (GGUM; Roberts, Donoghue, \& Laughlin, 2000), which is an approach towards reproducing response patterns for self-report measures of personality (e.g., Stark, Chernyshenko, Drasgow, \& Williams, 2006), attitudes (e.g., Carter \& Dalal, 2010), and affect (LaPalme, Tay, \& Wang, 2017). Most importantly for the current investigation, the ideal point approach to scoring has been shown to more accurately recover curvilinear relationships in simulated (Carter, Dalal, Guan, LoPilato, \& Withrow, 2017) and empirical (Carter et al., 2014, 2016) data.

\section{Method}

\section{Sample 1: Participants and Procedure}


Sample 1 comprised 787 participants recruited from the research pool at a large Southern state university in the United States in exchange for research credit $(53 \%$ men; mean age $=$ 19.34; $S D=2.19 ; 83 \%$ Caucasian; 7\% Asian; 6\% African American). Upon signing informed consent, participants completed a packet of self-report questionnaires and were debriefed. Some of these data were used in previous studies on the factor structure of the EPA and the validity of brief psychopathy measures (Few, Miller, \& Lynam, 2013; Miller, Few, et al., 2012), not for tests of curvilinearity. Institutional review board approval was provided for this study.

\section{Sample 2: Participants and Procedure}

Participants included 865 participants recruited from Amazon's Mechanical Turk (MTurk) website. Research utilizing MTurk has shown that the MTurk population is a reliable source of data with more demographic diversity than most undergraduate populations (Chandler \& Shapiro, 2016; Miller, Crowe, Weiss, Maples-Keller, \& Lynam, 2017). To participate, participants had to be 18 years of age or older and reside in the United States. Participants were paid \$2.00 for their participation. Of the 865 participants who completed informed consent, 269 participants were removed for failing one or both validity scales (see Measures section), for finishing the study in a time deemed invalid ( $>20$ minutes), for having more than $25 \%$ missing data, or for random responding. The final dataset consisted of 596 participants $(63 \%$ female; 83\% White; 10\% Black; 8\% Asian; 6\% Hispanic; $\mathrm{M}$ age $=37.04, \mathrm{SD}=11.75) .^{2}$ Some of these data were used in previous studies clarifying the nomological network of narcissism (Crowe, Sleep, Carter, Campbell, \& Miller, 2018; Miller, Lynam, Siedor, et al., 2018; Miller, Lynam, Vize, et al., 2018; Vize et al., 2017), not for studies on psychopathy in general and curvilinearity more specifically. Institutional review board approval was provided for this study.

\footnotetext{
${ }^{2}$ Participants could endorse more than a single racial category and thus these percentages sum to greater than $100 \%$.
} 


\section{Measures}

Psychopathic Personality Inventory-Revised (PPI-R). ${ }^{3}$ The PPI-R (Lilienfeld \&

Widows, 2005) is a 154-item measure of psychopathy that provides scores for eight subscales, as well as a global psychopathy score and two psychopathy factor scores (PPI-R Fearless Dominance [PPI FD] and PPI-R Self-centered Impulsivity [PPI SCI]). The PPI-R was given in Sample 1. Alphas for the 8 PPI-R subscales range from .83 to .88 with a median of .85 .

Triarchic Psychopathy Measure. (TriPM). The TriPM (Patrick et al., 2009) is a 58-item self-report measure of psychopathy that provides a global psychopathy score $(\alpha=.87)$ as well as three scales: Boldness (19 items; $\alpha=.87$ ), Meanness (18 items; $\alpha=.89$ ), and Disinhibition (20 items; $\alpha=.87$ ). While there are typically 19 items in the TriPM Meanness scale, one item ("I sympathize with others' problems") was dropped from the scale due to misfit. See discussion in Scoring Methods. The TriPM was used in Sample 2.

Crime and Analogous Behavior Scale (CAB). The CAB (Miller \& Lynam, 2003) is a self-report inventory that assesses a variety of externalizing behaviors. A substance use variety count was created by giving participants a " 1 " for every substance they endorsed using (6 items; $\mathrm{M}=1.96$; $\mathrm{SD}=1.43$ ). An antisocial behavior count was created by giving participants a " 1 " for every antisocial act they endorsed (10 items; $\mathrm{M}=.90 ; \mathrm{SD}=1.03)$. The following acts were included in the antisocial behavior scale: theft (of more and less than $\$ 50$ value), car theft, physical fighting, threat with a weapon, assault with a weapon, intentional injury of another person, burglary, and been arrested (for DUI and something other than DUI). Because these represent counts of behaviors, special analytic approaches for counts were used. The full CAB was given in Sample 1, whereas a brief version was used in Sample 2. In Sample 2, a substance

\footnotetext{
${ }^{3}$ The data analyzed from both samples were collected as part of larger assessment batteries that included measures not related to the current study. Not all measures collected are reported here.
} 
use variety count was created by giving participants a "1" for every substance they endorsed using ( 5 items; $\mathrm{M}=1.84 ; \mathrm{SD}=1.36$ ). An antisocial behavior count was created by giving participants a "1" for every antisocial act they endorsed (10 items; $\mathrm{M}=1.08 ; \mathrm{SD}=1.40$ ).

Reactive and Proactive Aggression Questionnaire (RPA). The RPA (Raine et al., 2006) scale consists of 23 self-report items assessing two aggression scales: Proactive Aggression (12 items; $\mathrm{M}=1.51, \mathrm{SD}=2.44$ ) and Reactive Aggression (11 items; $\mathrm{M}=6.83, \mathrm{SD}=3.66)$. Items are scored in the following manner: 0 (never), 1 (sometimes), and 2 (often). In Sample 2, the coefficient alphas for the proactive and reactive scales were both .82 . Reactive and proactive aggression were substantially correlated, $r=.55$.

Validity Scales. Two validity scales from the Elemental Psychopathy Assessment (Lynam et al., 2011) were used, the Infrequency Scale and the Too Good to be True Scale. Participants were removed from the analyses if they received a score of four or more on the Infrequency Scale or a score of three or more on the Too Good to be True Scale.

\section{Data Analysis}

\section{Scoring Methods}

In the current investigation, we utilize IRT scoring for all self-report measures, except those that are based on behavioral count data. The use of IRT-based scores is particularly important to the current investigation due to recent findings that they yield more accurate tests of curvilinearity (Carter et al., 2017). IRT models generally assume that participant's responses to test items are influenced by characteristics of the person as well as the idiosyncratic characteristics of the measure administered. Responses are thought to be only partially determined by the level of the measured personality trait possessed by the respondent. IRT models also propose that responses are determined by the extremity of the item content, which is 
alternatively referred to as item difficulty, location, or popularity. Finally, IRT models consider that responses are also partially determined by the extent to which the item can differentiate between those with higher versus lower trait standing, referred to as discrimination (which can be thought of as similar to factor loadings). By accounting for item-level idiosyncrasies in test scoring, IRT scoring controls the type 1 error in tests for curvilinearity caused by items whose content expresses more extreme levels of the trait than most persons being assessed, which Carter et al. (2017) showed is typical of commonly-used personality measures.

Dominance vs. Ideal Point Models. Although IRT scoring generally increases the accuracy of tests for curvilinearity, Carter et al. (2016) pointed out that it is also crucial to utilize an IRT model that appropriately characterizes the item response process (i.e., the way respondents "use" the scale to respond to the item content). The majority of IRT models (as well as classical sum-scores and factor scores) assume a dominance response process which implies that those with higher levels of a personality trait will always be more likely to endorse a positively keyed item. Although this assumption is sensible for measures of ability - in which respondents attempt to "dominate" the item, or answer correctly - and measures based on behavioral frequency, recent work has cast doubt on the validity of the dominance assumption for personality tests with Likert-type endorsement scales (e.g., LaPalme et al., 2017; Stark et al., 2006; Roberts, Laughlin, \& Wedell, 1999).

Counter to the assumption of a dominance process, ideal point models assume that individuals are most likely to endorse items with content that matches their own personality trait level. Thus, under ideal point model assumptions, an individual can be less likely to fully endorse an item (i.e., "strongly agree") both because the item is too extreme and because the item is not extreme enough. For example, a statement such as "I keep my room clean most of the 
time" may not be endorsed by persons low in conscientiousness because they do not keep their room clean, but may also not be endorsed by persons with very high conscientiousness because they keep their room clean all the time, not just "most of the time."

There is debate regarding the necessity of ideal point models for personality constructs (Drasgow et al., 2010; c.f., Reise, 2010), but research has shown the ideal point assumption generally shows better fit to self-report personality measures (e.g., Stark et al., 2006). While overall scores within a sample may not show substantial differences across the two scoring approaches, assuming a dominance process when an ideal point process is more appropriate causes confusion in rank-order at the top end of the trait distribution (see Roberts et al., 1999). Thus, ideal point models have proven particularly useful for uncovering curvilinear relationships where they exist (Carter et al., 2014, 2016), and reducing false flags (i.e., type 1 errors; Carter et al., 2017). However, as noted previously, the advantage of IRT scoring is predicated on the correct choice of an IRT model for scoring personality tests (Carter et al., 2016). Therefore, we consider the fit of both ideal point and dominance IRT models in the current investigation.

Model Estimation and Fit. The generalized partial credit model (GPCM; Muraki, 1992) assumes a dominance response process and is appropriate for polytomous Likert-type scores. The generalized graded unfolding model (GGUM; Roberts et al., 2000) assumes an ideal point response process and is suited for polytomous Likert-type responses. The GPCM was estimated using the 'mirt' package in R (Chalmers, 2012), and the GGUM was estimated using the GGUM2004 software program (Roberts, Fang, Cui, \& Wang, 2006). Both programs utilize marginal maximum likelihood (MML) estimation to determine item parameters and Expected a Posteriori (EAP) scoring to determine persons' trait levels. 
See Supplemental Tables for all fit statistics used for model selection. Relative modeldata fit for the GPCM (i.e., dominance model) and GGUM (i.e., ideal point model) was evaluated by comparing the Akaike Information Criterion (AIC; Akaike, 1973; Bozdogan, 1987). The GGUM showed superior model-data fit for all measures in Sample 1. GPCM showed superior model-data fit for all measures in Sample 2. The MODFIT program (Stark, 2007) was used to evaluate absolute model-data fit (i.e., $\chi^{2} / d f$ ratios) of the GGUM (Sample 1) and GPCM (Sample 2). Evaluation of absolute model-data fit was necessary to verify that the data meets model assumptions of unidimensionality, which has been called into question for the TriPM Boldness domain (Shou et al., in press). The $\chi^{2} / d f$ ratio compares the actual responses in the data to the responses predicted by the IRT model via the $\chi^{2}$ statistic divided by the degrees of freedom for the test; ratios greater than three are generally considered to indicate model-data misfit.

In Sample 1, all PPI-R GGUM models showed ratios less than three. In Sample 2, GPCM TriPM Boldness and Disinhibition models showed acceptable model-data fit. As both the GGUM and GPCM assume unidimensionality, adequate model-data fit is indicative of an acceptable unidimensional structure for these traits. TriPM Meanness manifested unacceptable model-data fit as all ratios were greater than three. Further evaluation revealed that the misfit of the model was the result of multidimensionality. Once the single worst fitting item ("I sympathize with others' problems") was removed, model-data fit was appropriate with all ratios falling below three. All analyses were conducted using estimates from this 18 -item version of the scale.

The GGUM was used to estimate all component scores in Sample 1. PPI-R domain-level scores were also generated in Sample 1. GGUM estimates of measured traits $(\theta)$ were averaged to generate higher-order factor scores. The PPI-R SCI factor was estimated by averaging Blame 
Externalization, Carefree Nonplanfulness, Machiavellian Egocentricity, and Rebellious Nonconformity scores. The PPI-R FD factor was estimated by averaging Fearlessness, Social Influence, and Stress Immunity scores. The GPCM was used to estimate all TriPM scores for Sample 2 as well as reactive and proactive aggression scores.

In IRT, test information is conceptually similar to scale reliability and can be thought of as the scale's measurement precision at a particular level of the latent trait, $\theta_{j}$. Test information can be used to generate at Test Reliability Function (TRF), which depicts measurement reliability at all levels of the latent trait. The TRF and observed distribution of latent psychopathy traits were examined as part of our evaluation of the samples' appropriateness for testing the curvilinearity hypothesis. Histograms of latent traits and response distributions were also examined.

\section{Regression Models}

As count data (such as the CAB) often deviate from the assumptions of OLS regression, alternative models were applied in the present analyses. Poisson regression is often applied to count data and assumes that the variance of data is congruent with the mean. When the variance of data deviates substantially from the mean, negative binomial regression is more appropriate. Negative binomial regression accounts for overdispersion (i.e., when variance exceeds the mean) by estimating an additional dispersion parameter $(\alpha)$ and applying more conservative tests of significance in proportion to the degree of dispersion and standard error (Atkins, Baldwin, Zheng, Gallop, \& Neighbors, 2013). For all regressions, the appropriateness of modeling with Poisson and negative binomial was evaluated by comparing model fit using Bayesian Information Criterion (BIC; Raftery, 1995), which includes a correction for the increased complexity of the negative binomial model. Poisson and negative binomial regressions were only 
considered for the $\mathrm{CAB}$. For the non-count data outcomes (i.e., reactive and proactive aggression) standard OLS regression with robust standard errors was used.

To examine curvilinearity, all latent trait scores were standardized, and the polynomial term was calculated from the standardized value (Cohen, Cohen, West, Aiken, 2002). In the first step of all analyses standardized psychopathy scores (i.e., GGUM latent trait estimates) were entered as a predictor of externalizing behavior. In the second step, the squared value of the standardized psychopathy score was entered as an additional predictor and the change in modeldata fit was evaluated to assess for curvilinearity.

The incremental contribution of the curvilinear effect for each model was evaluated using BIC (Raftery, 1995), and $R^{2}$ or Pseudo $R^{2}$ (McFadden, 1974). BIC was the primary fit index used when evaluating whether the curvilinear model indicated considerable improvement upon the simpler linear model. Raftery's (1995) suggestion of a BIC difference greater than two was used as positive evidence of a better fitting model. McFadden's (1974) pseudo- $R^{2}$ calculation was used for all Poisson and negative binomial models, which do not have a statistical equivalent to OLS $R^{2}$. Although the intended use of McFadden's pseudo- $R^{2}$ is similar to the OLS $R^{2}$ metric, its values tend to be much smaller and cannot be interpreted as variance accounted for by the model. McFadden $R^{2}$ values ranging from .2 to .4 are thought to be indicative of excellent model fit, comparable to OLS $R^{2}$ values of .7-.9 (McFadden, 1979).

To examine interaction effects, the standardized latent trait estimates were entered as predictors of externalizing behavior along with the product term of the predictors. When a significant interaction term was identified, simple effects were evaluated at one standard deviation above and below the mean of the non-FD/B term. All potential domain level FD/B 
interaction effects were evaluated (i.e., FD x SCI; FD x Coldheartedness; Boldness x Meanness; Boldness x Disinhibition).

\section{Results}

Item response theory models estimate individual latent traits scores $(\theta)$. These scores are on a standardized scale with zero being the population mean of the latent trait and one being one standard deviation above the population mean of that trait. Histograms of all $\theta$ score distributions and outcome counts are included in the supplemental materials along with additional descriptive statistics of the raw and latent trait scores (Supplemental Table 5) and graphs of all Test Reliability Functions (TRFs; Supplemental Figures 8-11). In Sample 1, the average maximum latent trait score across PPI-R scales was 3.04 standard deviations above the population mean and the average range was 6.14 standard deviations wide. The smallest maximum latent trait score was 2.06 (Carefree Nonplanfulness; range $=-3.68$ to 2.06). The largest raw Carefree Nonplanfulness score was 45 out of a possible 57 and a total of 9 participants endorsed ${ }^{4}$ at least three quarters of the scale (i.e., 15 of 19 items) or more. The largest maximum latent trait score was 4.29 (Social Dominance; range $=-4.36$ to 4.29 ). The largest raw Social Dominance score was 52 out of a possible 54 and 202 participants endorsed at least three quarters of the scale (i.e., 14 of 18 items). Sample 1 test reliability functions revealed marginal reliabilities at three standard deviations above the population mean that ranged from .68 (Stress Immunity) to .88 (Carefree Nonplanfulness). In Sample 2, the average maximum TriPM latent trait score was 3.22 standard deviations above the population mean and the average range was 5.64 standard deviations wide. The smallest maximum latent trait score was 3.09 (Meanness; range $=-1.76$ to 3.09). The largest raw Meanness score was 65 out of a possible 72, and three participants

\footnotetext{
${ }^{4}$ Accounts for reverse scoring and refers to individuals who responded "mostly true" or "true" in the case of the PPI-R, "somewhat true" or "true" in the case of the TriPM. and "sometimes" or "often" in the case of the RPA.
} 
endorsed at least three quarters of the scale (i.e., 14 of 18 items). The largest maximum latent trait score was 3.41 (Reactive aggression; range $=-2.09$ to 3.41 ). The largest raw reactive aggression score was 22 out of a possible 22, and 128 participants endorsed at least three quarters of the scale (i.e., 9 of 11 items). Sample 2 test reliability functions revealed marginal reliabilities at three standard deviations above the population mean that ranged from .70 (Boldness) to .92 (Meanness).

Psychopathy scale correlations are reported in Supplemental Table 1. Results of all curvilinear regression analyses are reported in Tables 1-4. Over-dispersion was evaluated for all models predicting $\mathrm{CAB}$ externalizing outcomes by comparing the BIC fit of the Poisson model to the negative binomial model. Results indicated that Poisson regression was appropriate when using PPI-R scores to predict CAB outcomes in nearly all cases. Only the prediction of CAB antisocial behavior from PPI-R Social Influence required the use of negative binomial analyses. When TriPM subscales were used, Poisson was most appropriate for substance use, while negative binomial analysis was most appropriate for antisocial behavior. Model fit was also evaluated for the reactive and proactive aggression scales. Fit suggested that while ordinary least squares (OLS) analyses were acceptable for the prediction of reactive aggression, negative binomial analyses were more appropriate for the prediction of proactive aggression.

Note that both Poisson and negative binomial regression predict the natural log of the expected count variable. Unless otherwise indicated, all reported coefficients are reported in log units. To convert coefficients to count units they must be exponentiated (i.e., $e^{x}$ ). However, to do so changes their interpretations from additive to multiplicative (see Coxe, West, \& Aiken, 2009 for review).

\section{Evaluating Curvilinearity}


Substance Use. Step 1 of all analyses evaluated only linear effects. All eight of the PPI-R facets and both factor score estimates showed statistically significant linear effects when predicting substance use. PPI-R standardized regression coefficients ranged in size from .06 ( $p<$ .05 ; Stress Immunity) to .18 ( $p<.01$; Fearlessness). When TriPM scales were used to predict substance use, regression coefficients ranged in size from $.02(p=n s ;$ Boldness $)$ to $.19(p<.01$; Disinhibition). In Step 2 of all regression analyses linear and quadratic terms were included. When predicting substance use, all PPI-R SCI scales (i.e., Blame Externalization, Carefree Nonplanfulness, Machiavellian Egocentricity, and Rebellious Nonconformity) and Coldheartedness yielded statistically significant quadratic effects ranging in magnitude from -.12 $(p<.01$; Machiavellian Egocentricity) to -.04 ( $p<.05$; Blame Externalization). Of these five effects, BIC values indicate that only the quadratic effects of Machiavellian Egocentricity, Rebellious Nonconformity, and Coldheartedness represent meaningful improvements over the linear model. At the factor level, PPI-R SCI also yielded a statistically significant quadratic effect that improved model fit. No TriPM facets to show a meaningful quadratic effect for the prediction of substance use. All identified quadratic effects are negative in direction, which indicates a reduction in substance use at higher latent trait levels, contrary to the direction hypothesized (Blonigen, 2013) (See Supplemental Figures 1-4).

Antisocial Behavior. In Step 1 of analyses predicting antisocial behavior, seven of eight PPI-R subscales and two of three TriPM subscales showed statistically significant effects. PPI-R subscale coefficients ranged in size from .04 ( $p=$ ns; Social Influence) to $.28(p<.01$; Fearlessness). TriPM subscales ranged from .08 ( $p=$ ns; Boldness) to .48 $(p<.01$; Disinhibition). In Step 2, PPI-R Fearlessness (-.05; $p<.05)$, Machiavellian Egocentricity (-.14; $p$ $<.01)$, Blame Externalization $(-.07 ; p<.05)$, and the SCI factor $(-.16 ; p<.05)$ showed 
statistically significant quadratic effects. Of these, only Machiavellian Egocentricity meaningfully improved the fit of the model. Again, the directionality of the curve was the opposite of the hypothesized direction (See Supplemental Figure 5).

Reactive and Proactive Aggression. In Step 1, all TriPM subscales were significant linear predictors of reactive aggression with standardized coefficients ranging from -.13 $(p<.01$; Boldness) to .42 ( $p<.01$; Disinhibition). Only Boldness failed to predict proactive aggression with coefficients ranging from -.01 ( $p=\mathrm{ns}$; Boldness) to $.36(p<.01$; Disinhibition). Significant quadratic effects were found when Meanness and Disinhibition were used to predict proactive aggression. These effects were consistent with Blonigen's hypothesized direction, albeit for different psychopathy domains (See Supplemental Figures 6 and 7).

\section{Evaluating Interactions}

No significant interactions were identified between FD and SCI or FD and Coldheartedness. An interaction between Boldness and Meanness was identified when predicting substance abuse $\left(\beta_{0}=.59, p<.001 ; \beta_{\mathrm{B}}=.03, p=.389 ; \beta_{\mathrm{M}}=.05, p=.087 ; \beta_{\mathrm{B}^{* \mathrm{M}}}=.09 p=.003\right)$. Boldness was positively associated with substance abuse, but only at high levels of Meanness ($1 S D$ Meanness: $\beta_{\mathrm{B}}=-.19, p=.003 ;+1 S D$ Meanness: $\left.\beta_{\mathrm{B}}=.20, p=.005\right)$. An interaction between Meanness and Disinhibition was also identified when predicting proactive aggression $\left(\beta_{0}=-.07\right.$, $\left.p=.02 ; \beta_{\mathrm{M}}=.17, p<.001 ; \beta_{\mathrm{D}}=.28, p<.001 ; \beta_{\mathrm{B} * \mathrm{M}}=.14 p<.001\right)$, such that high levels of meanness increased the association between disinhibition and proactive aggression $(-1 S D$ Meanness: $\beta_{\mathrm{D}}=.22, p<.001 ;+1 S D$ Meanness: $\left.\beta_{\mathrm{D}}=.57, p<.001\right)$. No other significant interactions were found.

\section{Discussion}

There have been two primary explanations offered for FD/B's failure to relate to 
externalizing outcomes characteristic of psychopathy. The first hypothesis, put forward by Blonigen (2013), suggests that FD/B's relevance to these maladaptive outcomes may only be seen at high levels of these traits. To date, this hypothesis has been tested three times with each finding no evidence to suggest a curvilinear relation with behavioral outcomes typical of psychopathy (Gatner et al., 2016; Vize et al., 2016, Weiss et al., in press). Second, some researchers have argued that $\mathrm{FD} / \mathrm{B}$ may be more relevant to these outcomes through synergistic interactions with antagonism/meanness and disinhibition in predicting maladaptive behavioral outcomes (Lilienfeld et al., 2012). However, these interactions do not materialize consistently (e.g., Gatner et al., 2016; Maples et al., 2014; Miller, Maples-Keller, \& Lynam, 2016; Vize et al., 2016; cf., Marcus \& Norris, 2014; Rock et al., 2013).

Effectively evaluating curvilinear effects at extreme ends of the trait continuum requires sufficient variability of psychopathic traits within the sample. Sample 1 included latent trait estimates more than three standard deviations greater than the population mean for all facets of FD. Each facet of FD also had over 100 individuals endorse at least three quarters of the item content. Sample 2 also included Boldness latent trait estimates exceeding three standard deviations beyond the population mean and over 100 individuals endorsed at least three quarters of the items. Equally important, the Test Reliability Function suggested that individuals at extreme ends of all PPI-R and TriPM traits were reliably measured. Samples 1 and 2 therefore seem to include sufficient variance for providing a reasonable test of Blonigen's (2013) curvilinearity hypothesis. There are fewer observations at the extreme ends of the PPI-R SCI facets in Sample 1, and Meanness and Disinhibition factors in Sample 2, but extreme responses were observed. Latent trait estimates greater than three were measured for three of the four PPI$\mathrm{R}$ facets (the only exception being Carefree Nonplanfulness) and all TriPM facets. The amount 
of raw item endorsement was relatively small for Carefree Nonplanfulness in Sample 1 and Meanness and Disinhibition in Sample 2. This may have made some of the interaction hypotheses more difficult to identify. However, not all Sample 1 SCI factors were so limited. In Sample 1, Machiavellian Egocentricity and Rebellious Nonconformity included in excess of 30 individuals that endorsed at least three quarters of the scale.

Our analysis found no evidence for a curvilinear relation between FD/B and externalizing outcomes. However, it is noteworthy that in Sample 1, FD, and Fearlessness in particular, had linear effects comparable to the SCI domain. This is consistent with factor analyses which show that Fearlessness tends to load on both FD and SCI factors suggesting that, relative to other facets of the FD domain, it may contain more antagonism and disinhibition (both definitive features of SCI) content (Benning et al., 2003; Neumann et al., 2008; Weiss et al., 2019). This finding also highlights the importance of considering associations at the level of subscales rather than domain scores. One curvilinear effect was observed for Fearlessness in the prediction of antisocial behavior counts, but the effect was negative (indicating a reduction in antisocial behavior at higher ends of the spectrum) and small in magnitude. Additional quadratic effects were identified but these were observed for non-FD/B scales.

In line with the interaction hypothesis, a Boldness $\mathrm{x}$ Meanness interaction was found suggesting that Boldness, when paired with high Meanness, is positively associated with substance use. This was, however, the only statistically significant FD/B interaction observed in the two samples. These findings provide little evidence for the hypothesis that FD/B domains interact with other components of psychopathy to increase problematic externalizing behavior. These null effects are consistent with previous tests of the hypothesis (Vize et al., 2016; Gatner et al., 2016; Weiss et al., in press). It is important to acknowledge that null findings are often 
difficult to interpret due to potential alternative explanations related to shortcomings in study design (e.g., small sample size, measurement error). While we cannot be certain that no such shortcomings have resulted in our failure to observe the hypothesized effects (see also the Limitations section below), unique aspects for of these analyses provide some support for the validity of our findings. The GGUM IRT model was utilized as it is the most precise statistical tool available for latent trait measurement. Furthermore, as verified by Monte Carlo simulations (see Supplemental Power Analysis), our analyses were powered to detect relatively small effects.

Taking our results together with previous findings suggests that there is little evidence in favor of the interaction or curvilinearity hypotheses. Consistent with findings from relevant meta-analyses (Miller \& Lynam, 2012; Sleep et al., 2019), our results suggest that FD/B manifest small positive linear associations with certain externalizing outcomes. For instance, the FD subscales were positively linearly related to substance use and antisocial behavior. No such linear associations were found for boldness.

PPI-R SCI subscales, PPI-R Coldheartedness, TriPM Disinhibition, and TriPM Meanness were also evaluated for curvilinear effects in the prediction of externalizing behavior. Statistically significant curvilinear relations were observed, but they were modest in size and negative in nearly all instances suggesting a reduction in, or perhaps more likely a leveling-off of externalizing behavior at high levels of the trait. Two of four PPI-R SCI scales (Machiavellian Egocentricity and Rebellious Nonconformity) and the PPI-R SCI factor revealed this pattern in the prediction of substance use in the undergraduate sample, as did Coldheartedness. Modest negative curvilinear effects were also found in the prediction of antisocial behavior, but only for PPI-R Machiavellian Egocentricity. These results are inconsistent with those of Weiss and colleagues (2019), who found modest positive curvilinear effects for Coldheartedness and 
Carefree Nonplanfulness in the prediction of Antisocial Behavior. Sample 2 revealed two curvilinear effects in the prediction of proactive aggression from TriPM Meanness and Disinhibition. Proactive aggression was more strongly associated with higher levels of Meanness and Disinhibition.

It is notable that in most instances, where curvilinear relations were found, the pattern of curvilinearity did not match the convex pattern that Blonigen (2013) hypothesized for FD/B domains. More often, the coefficient indicated a reduction in slope towards the extreme ends of the trait (See Supplemental Figures 1-7). For example, externalizing behavior appears to decline with increasing levels of PPI Machiavellian Egocentricity. ${ }^{5}$ It is possible that the identified curvature is indicative of a plateau effect such that beyond certain levels of these traits there is no longer a meaningful increase in externalizing behaviors. However, because associations at the most extreme ends of the trait continuum are necessarily driven by a relative few, it is also possible that the reduction observed was an idiosyncratic sample-driven effect. Such an explanation is more likely for SCI factors as well as Meanness and Disinhibition, each of which had fewer extreme responses (see Supplemental Table 5 and Supplemental Histograms). It will be important for future research to address the degree to which these curvilinear relations replicate and what they mean for psychopathy's relations with externalizing behaviors. Regarding the interaction hypothesis, our results are consistent with previous null findings. Of the 18 interactions tested, only one effect consistent with predictions was identified. Meanness moderated the association between Boldness and substance abuse with only individuals high in Meanness showing a positive association between boldness and drug use. There was also an interaction between Meanness and Disinhibition such that individuals high in

\footnotetext{
${ }^{5}$ Sample 1 means for ME exceeded offender sample means ( $d=0.50$; Lilienfeld \& Widows).
} 
both traits had particularly high proactive aggression scores, but this interaction falls outside the scope of the FD/B interaction hypothesis.

\section{Limitations}

Some limitations of the current study and approach must be acknowledged. First, Sample 1 was composed of a relatively homogeneous undergraduate sample. Although samples of this nature are commonly employed in the study of psychopathy (e.g., Berg, Hecht, Latzman, \& Lilienfeld, 2015; Blagov, Patrick, Oost, Goodman, \& Pugh, 2016), restriction of range could have affected the sizes of correlations found between psychopathy and criteria, particularly antisocial behavior and proactive aggression, which were both heavily skewed. The statistical methods used attempt to accommodate such distributions, but it is possible that stronger associations could be found in populations with higher base rates of such behaviors (e.g., forensic populations). Future examinations of the interaction hypothesis may require oversampling for externalizing behaviors.

Sample size may have been a related limitation. Although the study was well powered to detect most effects (see Supplemental Power Analysis), a larger sample would have allowed for additional data at the most extreme ends of the psychopathy spectrum. TriPM Disinhibition $(d=$ -1.811) and TriPM Meanness $(d=-1.16)$ means from our sample were more than one standard deviation below means from offender samples (Lilienfeld \& Widows, 2005; Stanley, Wygant, \& Sellbom, 2013). It is possible that interaction effects could be found in forensic samples with more extreme levels of such traits, although recent analyses limited to the PPI found no such interaction (Weiss et al., 2019). FD/B means from our samples adequately matched offender sample means suggesting that the range for the trait most central to the curvilinearity hypothesis was not particularly restricted. 
The number of outcome measures should also be considered. As we are aware of few specific hypotheses regarding which specific antisocial behaviors FD/B is most likely to predict and given the sample size needed to assess the hypothesized effects, we chose to briefly measure a few prominent outcomes while emphasizing sample size. Some have argued that, given FD/B's association with grandiose narcissism, it may predict antagonistic interpersonal behaviors observed among narcissistic individuals (e.g., entitlement, superiority, manipulativeness; Lilienfeld et al., 2012). It is possible that significant curvilinear or interaction effects could be found for FD/B were different outcome measures such as these collected.

\section{Conclusion}

These analyses used advanced statistical methods to evaluate two of the most prominent hypotheses for the role of FD/B in predicting externalizing outcomes. We found no evidence to support the curvilinearity hypothesis that FD/B traits are more strongly related to externalizing behaviors at higher levels. We also found little evidence to support the hypothesis that FD/B may interact with other components of psychopathy to result in externalizing behaviors. These hypotheses were tested in well-powered samples with common measures of FD/B.

No single study can provide definitive evidence of a null effect, but the absence of statistically significant findings in the present study are noteworthy. In this case, power simulations estimate $60-92 \%$ power to detect 22 boldness-related effects. Failure to find the hypothesized effects in the present paper contributes to a growing literature suggesting that FD/B may not be as relevant to psychopathy as some have proposed. If FD/B warrants a role in psychopathy, we believe it may be better understood as a peripheral feature, rather than an equal sized partner to antagonism/meanness and disinhibition, which are more strongly associated with the behavioral correlates that have made psychopathy the focus of such intense examination. 


\section{References}

Akaike, H. (1973). Maximum likelihood identification of Gaussian autoregressive moving average models. Biometrika, 60, 255-265.

Atkins, D. C., Baldwin, S. A., Zheng, C., Gallop, R. J., \& Neighbors, C. (2013). A tutorial on count regression and zero-altered count models for longitudinal substance use data. Psychology of Addictive Behaviors, 27, 166-177.

Benning, S. D., Patrick, C. J., Hicks, B. M., Blonigen, D. M., \& Krueger, R. F. (2003). Factor structure of the Psychopathic Personality Inventory: Validity and implications for clinical assessment. Psychological Assessment, 15, 340-350.

Berg, J. M., Hecht, L. K., Latzman, R. D., \& Lilienfeld, S. O. (2015). Examining the correlates of the coldheartedness factor of the Psychopathic Personality Inventory-Revised. Psychological Assessment, 27, 1494-1499.

Berg, J. M., Lilienfeld, S. O., \& Sellbom, M. (2017). The role of boldness in psychopathy: A study of academic and clinical perceptions. Personality Disorders: Theory, Research, and Treatment, 8, 319-328.

Blagov, P. S., Patrick, C. J., Oost, K. M., Goodman, J. A., \& Pugh, A. T. (2016). Triarchic Psychopathy Measure: Validity in relation to normal-range traits, personality pathology, and psychological adjustment. Journal of Personality Disorders, 30, 71-81.

Bleidorn, W., Hopwood, C. J., Ackerman, R A., Witt, E. A., Kandler, C., Riemann, R., Samuel, D. B., \& Donnellan, M. B. (in press). The healthy personality from a basic trait perspective. Journal of Personality and Social Psychology.

Blonigen, D. M. (2013). Is fearless dominance relevant to the construct of psychopathy? Reconciling the dual roles of theory and clinical utility. Personality Disorders: Theory, 
Research, and Treatment, 4, 87-88.

Bozdogan, H. (1987). Model selection and Akaike's information criterion (AIC): The general theory and its analytical extensions. Psychometrika, 52, 345-370.

Carter, N. T., Dalal, D. K., Boyce, A. S., O’Connell, M. S., Kung, M.-C., \& Delgado, K. M. (2014). Uncovering curvilinear relationships between conscientiousness and job performance: How theoretically appropriate measurement makes an empirical difference. Journal of Applied Psychology, 99, 564-586.

Carter, N. T., Dalal, D. K., Guan, L., LoPilato, A. C., \& Withrow, S. A. (2017). Item Response Theory Scoring and the Detection of Curvilinear Relationships. Psychological Methods, 22, 191-203.

Carter, N. T., Guan, L., Maples, J. L., Williamson, R. L., \& Miller, J. D. (2016). The downsides of extreme conscientiousness for psychological well-being: The role of obsessive compulsive tendencies. Journal of Personality, 84, 510-522.

Chalmers, R. P. (2012). mirt: A multidimensional item response theory package for the R environment. Journal of Statistical Software, 48, 1-29.

Chandler, J., \& Shapiro, D. (2016). Conducting clinical research using crowdsourced convenience samples. Annual Review of Clinical Psychology, 12, 53-81.

Cleckley, H. (1976). The mask of sanity: An attempt to clarify some issues about the so-called psychopathic personality. (5th ed.). St. Louis, MO: Mosby.

Cohen, J., Cohen, P., West, S. G., \& Aiken, L. S. (2002). Applied multiple regression/correlation analysis for the behavioral sciences, 3rd Edition (Third edition). Mahwah, N.J.: Routledge. 
Coxe, S., West, S. G., \& Aiken, L. S. (2009). The analysis of count data: A gentle introduction to poisson regression and its alternatives. Journal of Personality Assessment, 91, 121-136.

Crego, C., \& Widiger, T. A. (2014). Psychopathy, DSM-5, and a caution. Personality Disorders: Theory, Research, and Treatment, 5, 335-347.

Crego, C., \& Widiger, T. A. (2016). Cleckley's psychopaths: Revisited. Journal of Abnormal Psychology, 125, 75-87.

Crowe, M. L., Sleep, C. E., Carter, N. T., Campbell, W. K., \& Miller, J. D. (2018). Self-esteem and narcissism: An item response theory analysis of curvilinearity. Personality and Individual Differences, 128, 16-20.

Drasgow, F., Chernyshenko, O. S., \& Stark, S. (2010). 75 years after Likert: Thurstone was right! Industrial and Organizational Psychology, 3, 465-476.

Few, L. R., Miller, J. D., \& Lynam, D. R. (2013). An examination of the factor structure of the Elemental Psychopathy Assessment. Personality Disorders: Theory, Research, and Treatment, 4, 247-253.

Gatner, D. T., Douglas, K. S., \& Hart, S. D. (2016). Examining the incremental and interactive effects of boldness with meanness and disinhibition within the triarchic model of psychopathy. Personality Disorders: Theory, Research, and Treatment, 7, 259-268.

Hare, R. D. (1980). A research scale for the assessment of psychopathy in criminal populations. Personality and Individual Differences, 1, 111-119.

Hare, R. D. (2003). The psychopathy checklist revised: Toronto, ON.

Hare, R. D., \& Neumann, C. S. (2008). Psychopathy as a clinical and empirical construct. Annual Review of Clinical Psychology, 4, 217-246. 
Karpman, B. (1948). The myth of the psychopathic personality. American Journal of Psychiatry, 104, 523-534. https://doi.org/10.1176/ajp.104.9.523

Krusemark, E. A., Campbell, W. K., Crowe, M. L., \& Miller, J. D. (2018). Comparing self-report measures of grandiose narcissism, vulnerable narcissism, and narcissistic personality disorder in a male offender sample. Psychological Assessment, 30, 984-990.

LaPalme, M., Tay, L., \& Wang, W. (2017). A within-person examination of the ideal point response process. Psychological Assessment. doi: 10.1037/pas0000499

Levenson, M. R., Kiehl, K. A., \& Fitzpatrick, C. M. (1995). Assessing psychopathic attributes in a noninstitutionalized population. Journal of Personality and Social Psychology, 68, 151158.

Lilienfeld, S. O., \& Andrews, B. P. (1996). Development and preliminary validation of a selfreport measure of psychopathic personality traits in noncriminal population. Journal of Personality Assessment, 66, 488-524.

Lilienfeld, S. O., Patrick, C. J., Benning, S. D., Berg, J., Sellbom, M., \& Edens, J. F. (2012). The role of fearless dominance in psychopathy: Confusions, controversies, and clarifications. Personality Disorders: Theory, Research, and Treatment, 3, 327-340.

Lilienfeld, S. O., Smith, S. F., Sauvigné, K. C., Patrick, C. J., Drislane, L. E., Latzman, R. D., \& Krueger, R. F. (2016). Is boldness relevant to psychopathic personality? Meta-analytic relations with non-Psychopathy Checklist-based measures of psychopathy. Psychological Assessment, 28, 1172-1185.

Lilienfeld, S. O., \& Widows, M. R. (2005). PPI-R professional manual. Psychological Assessment Resources, Lutz, FL.

Lykken, D. T. (1995). The antisocial personalities. Hillsdale, NJ, England: Lawrence Erlbaum 
Associates, Inc.

Lynam, D. R., Gaughan, E., Miller, J. D., Miller, D., Mullins-Sweat, S., \& Widiger, T. A. (2011). Assessing the basic traits associated with psychopathy: Development and validation of the Elemental Psychopathy Assessment. Psychological Assessment, 23, $108-124$.

Lynam, D. R., \& Miller, J. D. (2012). Fearless dominance and psychopathy: a response to Lilienfeld et al. Personality Disorders: Theory, Research, and Treatment, 3, 341-353.

Maples, J. L., Miller, J. D., Fortune, E., MacKillop, J., Campbell, W. K., Lynam, D. R., .. . Goodie, A. S. (2014). An examination of the correlates of fearless dominance and selfcentered impulsivity among high-frequency gamblers. Journal of Personality Disorders, $28,379-393$.

Marcus, D. K., Fulton, J. J., \& Edens, J. F. (2012). "The two-factor model of psychopathic personality: Evidence from the Psychopathic Personality Inventory": Correction to Marcus, Fulton, and Edens (2011). Personality Disorders: Theory, Research, and Treatment, 4, 67-76.

Marcus, D. K., \& Norris, A. L. (2014). A new measure of attitudes toward sexually predatory tactics and its relation to the triarchic model of psychopathy. Journal of Personality Disorders, 28, 247-261.

McFadden, D. (1974). Conditional logit analysis of qualitative choice behavior. In Frontiers in Econometrics (pp. 105-142). New York: Academic Press.

McFadden, D. (1979). Quantitative methods for analyzing travel behaviour of individuals: Some recent developments. In D. Hensher \& P. Stopher (Eds.), Behavioural Travel Modelling (pp. 279-318). Croom Helm. 
Miller, J. D., Crowe, M. L., Weiss, B., Maples-Keller, J. L., \& Lynam, D. R. (2017). Using online, crowdsourcing platforms for data collection in personality disorder research: The example of Amazon's Mechanical Turk. Personality Disorders: Theory, Research, and Treatment, 8, 26-34.

Miller, J. D., Few, L. R., Seibert, L. A., Watts, A., Zeichner, A., \& Lynam, D. R. (2012). An examination of the Dirty Dozen measure of psychopathy: A cautionary tale about the costs of brief measures. Psychological Assessment, 24, 1048-1053.

Miller, J. D., Lamkin, J., Maples-Keller, J. L., \& Lynam, D. R. (2016). Viewing the triarchic model of psychopathy through general personality and expert-based lenses. Personality Disorders: Theory, Research, and Treatment, 7, 247-258.

Miller, J. D., \& Lynam, D. R. (2003). Psychopathy and the five-factor model of personality: A replication and extension. Journal of Personality Assessment, 81, 168-178.

Miller, J. D., \& Lynam, D. R. (2012). An examination of the Psychopathic Personality Inventory's nomological network: a meta-analytic review. Personality Disorders: Theory, Research, and Treatment, 3, 305-326.

Miller, J. D., Lynam, D. R., Siedor, L., Crowe, M., \& Campbell, W. K. (2018). Consensual lay profiles of narcissism and their connection to the Five-Factor Narcissism Inventory. Psychological Assessment, 30, 10-18. https://doi.org/10.1037/pas0000460

Miller, J. D., Lynam, D. R., Vize, C., Crowe, M., Sleep, C., Maples-Keller, J. L., ... Campbell, W. K. (2018). Vulnerable narcissism is (mostly) a disorder of neuroticism. Journal of Personality, 86. https://doi.org/10.1111/jopy.12303

Miller, J. D., Lynam, D. R., Widiger, T. A., \& Leukefeld, C. (2001). Personality disorders as extreme variants of common personality dimensions: can the five factor model 
adequately represent psychopathy?. Journal of Personality, 69, 253-276.

Miller, J. D., Maples-Keller, J. L., \& Lynam, D. R. (2016). An examination of the three components of the Psychopathic Personality Inventory: Profile comparisons and tests of moderation. Psychological Assessment, 28, 692-701.

Miller, J. D., Sleep, C. E., Crowe, M. L., \& Lynam, D. R. (2020). Psychopathic boldness: Narcissism, self-esteem, or something in between?. Personality and Individual Differences, 155, 1-5. https://doi.org/10.1016/j.paid.2019.109761

Muraki, E. (1992). A generalized partial credit model: Application of an EM algorithm. Applied Psychological Measurement, 6, 159-176.

Murphy, B., Lilienfeld, S., Skeem, J., \& Edens, J. F. (2016). Are fearless dominance traits superfluous in operationalizing psychopathy? Incremental validity and sex differences. Psychological Assessment, 28, 1597-1607.

Neumann, C. S., Malterer, M. B., \& Newman, J. P. (2008). Factor structure of the Psychopathic Personality Inventory (PPI): Findings from a large incarcerated sample. Psychological Assessment, 20, 169-174.

O'Boyle, E. H., Forsyth, D. R., Banks, G. C., Story, P. A., \& White, C. D. (2015). A metaanalytic test of redundancy and relative importance of the Dark Triad and Five-Factor Model of Personality. Journal of Personality, 83, 644-664.

Ozer, D. J., \& Benet-Martinez, V. (2006). Personality and the prediction of consequential outcomes. Annual Review of Psychology, 57, 401-421.

Paulhus, D. L., Neumann, C. F., \& Hare, R. D. (2017). Self-Report Psychopathy Scale $4^{\text {th }}$ Edition (SRP-4) Manual. Toronto, Ontario, Canada: Multi-Health Systems. 
Paulhus, D. L., Neumann, C. S., \& Hare, R. D. (2017). Self-report Psychopathy Scale: Technical Manual (4th ed.). Multi-Health Systems.

Patrick, C. J. (2010). Operationalizing the triarchic conceptualization of psychopathy: Preliminary description of brief scales for assessment of boldness, meanness, and disinhibition. Unpublished test manual, Florida State University, Tallahassee, Florida.

Patrick, C. J., Fowles, D. C., \& Krueger, R. F. (2009). Triarchic conceptualization of psychopathy: Developmental origins of disinhibition, boldness, and meanness. Developmental Psychopathology, 21, 913-938.

Raftery, A. E. (1995). Bayesian model selection in social research. Sociological Methodology, $25,111-163$.

Raine, A., Dodge, K., Loeber, R., Gatzke-Kopp, L., Lynam, D., Reynolds, C., ... Liu, J. (2006). The Reactive-Proactive Aggression Questionnaire: Differential Correlates of Reactive and Proactive Aggression in Adolescent Boys. Aggressive Behavior, 32, 159-171.

Reise, S. P. (2010). Thurstone Might Have Been Right About Attitudes, but Drasgow, Chernyshenko, and Stark Fail to Make the Case for Personality. Industrial and Organizational Psychology, 3(4), 485-488.

Roberts, J. S., Donoghue, J. R., \& Laughlin, J. E. (2000). A general item response theory model for unfolding unidimensional polytomous responses. Applied Psychological Measurement, 24, 3-32.

Roberts, J. S., Fang, H.-r., Cui, W., \& Wang, Y. (2006). GGUM2004: A Windows-based program to estimate parameters in the Generalized Graded Unfolding Model. Applied Psychological Measurement, 30, 64-65.

Roberts, J. S., Laughlin, J. E., \& Wedell, D. H. (1999). Validity issues in the Likert and 
Thurstone approaches to attitude measurement. Educational and Psychological Measurement, 59, 211-233.

Rock, R. C., Sellbom, M., Ben-Porath, Y. S., \& Salekin, R. T. (2013). Concurrent and predictive validity of psychopathy in a batterers' intervention sample. Law and Human Behavior, $37,145-154$.

Ross, S. R., Benning, S. D., Patrick, C. J., Thompson, A., \& Thurston, A. (2009). Factors of the Psychopathic Personality Inventory: Criterion-related validity and relationship to the BIS/BAS and five-factor models of personality. Assessment, 16, 71-87.

Sellbom, M., \& Phillips, T. R. (2013). An examination of the triarchic conceptualization of psychopathy in incarcerated and nonincarcerated samples. Journal of Abnormal Psychology, 122, 208-214.

Shou, Y., Sellbom, M., \& Xu, J. (in press). Psychometric properties of the Triarchic Psychopathy Measure: An Item Response Theory approach. Personality Disorders: Theory, Research, and Treatment.

Skeem, J. L., \& Cooke, D. J. (2010). Is criminal behavior a central component of psychopathy? Conceptual directions for resolving the debate. Psychological Assessment, 22, 433-455.

Sleep, C. E., Weiss, B., Lynam, D. R., \& Miller, J. D. (2019). An examination of the Triarchic Model of psychopathy's nomological network: A meta-analytic review. Clinical Psychology Review, 71, 1-26.

Smith, S. F., Lilienfeld, S. O., Coffey, K., \& Dabbs, J. M. (2013). Are psychopaths and heroes twigs off the same branch? Evidence from college, community, and presidential samples. Journal of Research in Personality, 47, 634-646.

Stanley, J. H., Wygant, D. B., \& Sellbom, M. (2013). Elaborating on the construct validity of the 
triarchic psychopathy measure in a criminal offender sample. Journal of Personality Assessment, 95, 343-350.

Stark, S. (2007). MODFIT: Plot theoretical item response functions and examine the fit of dichotomous or polytomous IRT models to response data [computer program]. Champaign, IL: University of Illinois at Urbana-Champaign.

Stark, S., Chernyshenko, O. S., Drasgow, F., \& Williams, B. A. (2006). Examining assumptions about item responding in personality assessment: should ideal point methods be considered for scale development and scoring? Journal of Applied Psychology, 91, 25-39.

Vize, C. E., Collison, K. L., Crowe, M. L., Campbell, W. K., Miller, J. D., \& Lynam, D. R. (2017). Using Dominance Analysis to Decompose Narcissism and Its Relation to Aggression and Externalizing Outcomes. Assessment.

Vize, C. E., Lynam, D. R., Lamkin, J., Miller, J. D., \& Pardini, D. (2016). Identifying essential features of juvenile psychopathy in the prediction of later antisocial behavior: Is there an additive, synergistic, or curvilinear role for Fearless Dominance? Clinical Psychological Science, 4, 572-590.

Weiss, B., Crowe, M. L., Harris, A., Carter, N. T., Lynam, D., Watts, A. L., ... Skeem, J. (2019). Examining hypothesized interactive and curvilinear relations between psychopathic traits and externalizing problems in an offender sample using item response-based analysis. Journal of Abnormal Psychology, 128, 689-699.

Witt, E. A., Donnellan, M. B., Blonigen, D. M., Krueger, R. F., \& Conger, R. D. (2009). Assessment of fearless dominance and impulsive antisociality via normal personality measures: Convergent validity, criterion validity, and developmental change. Journal of Personality Assessment, 91, 265-276. 
Table 1

Substance Abuse Regression Analyses

\begin{tabular}{|c|c|c|c|c|c|c|c|c|c|}
\hline \multirow[b]{2}{*}{ PPI-R Facet } & \multirow[b]{2}{*}{ Parameter } & \multicolumn{4}{|c|}{ Step 1} & \multicolumn{4}{|c|}{ Step 2} \\
\hline & & $B$ & {$[95 \% \mathrm{CI}]$} & $\mathrm{BIC}$ & Pseudo- $R 2$ & $B$ & {$[95 \% \mathrm{CI}]$} & $\mathrm{BIC}$ & Pseudo- $R 2$ \\
\hline \multirow[t]{3}{*}{ SCI Factor } & Intercept & $.66^{* *}$ & {$[.61, .71]$} & 2733.42 & .028 & $.74 * *$ & {$[.67, .80]$} & 2728.89 & .038 \\
\hline & Linear & $.19 * *$ & {$[.12, .26]$} & & & $.17 * *$ & {$[.10, .25]$} & & \\
\hline & Quadratic & & & & & $-.13 * *$ & {$[-.22,-.05]$} & & \\
\hline \multirow[t]{3}{*}{ BE $\theta$} & Intercept & $.67 * *$ & {$[.62, .72]$} & 2760.29 & .014 & $.71 * *$ & {$[.64, .77]$} & 2762.82 & .018 \\
\hline & Linear & $.10 * *$ & {$[.05, .16]$} & & & $.09 * *$ & {$[.03, .15]$} & & \\
\hline & Quadratic & & & & & $-.04 *$ & {$[-.08, .00]$} & & \\
\hline \multirow[t]{3}{*}{$\mathrm{CN} \theta$} & Intercept & $.66^{* *}$ & {$[.61, .72]$} & 2746.72 & .023 & $.71 * *$ & {$[.65, .78]$} & 2748.44 & .028 \\
\hline & Linear & $.13 * *$ & {$[.08, .19]$} & & & $.12 * *$ & {$[.07, .18]$} & & \\
\hline & Quadratic & & & & & $-.05 *$ & {$[-.10, .00]$} & & \\
\hline \multirow[t]{3}{*}{ ME $\theta$} & Intercept & $.67 * *$ & {$[.62, .72]$} & 2756.38 & .015 & $.77 * *$ & {$[.71, .82]$} & 2719.04 & .054 \\
\hline & Linear & $.10^{* *}$ & {$[.05, .16]$} & & & $.13^{* *}$ & {$[.06, .19]$} & & \\
\hline & Quadratic & & & & & $-.12 * *$ & {$[-.16,-.08]$} & & \\
\hline \multirow[t]{3}{*}{$\mathrm{RN} \theta$} & Intercept & $.67 * *$ & {$[.62, .72]$} & 2744.86 & .018 & $.75^{* *}$ & {$[.69, .81]$} & 2733.34 & .034 \\
\hline & Linear & $.12 * *$ & {$[.06, .17]$} & & & $.11 * *$ & {$[.06, .17]$} & & \\
\hline & Quadratic & & & & & $-.09 * *$ & {$[-.14,-.04]$} & & \\
\hline \multirow[t]{3}{*}{ FD Factor } & Intercept & $.66^{* *}$ & {$[.61, .71]$} & 2739.94 & .029 & $.69 * *$ & {$[.63, .74]$} & 2744.08 & .032 \\
\hline & Linear & $.20 * *$ & {$[.13, .26]$} & & & $.22 * *$ & {$[.14, .30]$} & & \\
\hline & Quadratic & & & & & -.05 & {$[-.10, .01]$} & & \\
\hline \multirow[t]{3}{*}{$\mathrm{F} \theta$} & Intercept & $.66^{* *}$ & {$[.61, .71]$} & 2725.01 & .043 & $.65 * *$ & {$[.60, .71]$} & 2731.63 & .043 \\
\hline & Linear & $.18^{* *}$ & {$[.13, .23]$} & & & $.18^{* *}$ & {$[.13, .23]$} & & \\
\hline & Quadratic & & & & & .00 & {$[-.03, .03]$} & & \\
\hline \multirow[t]{3}{*}{ Social $\theta$} & Intercept & $.67 * *$ & {$[.62, .72]$} & 2762.15 & .009 & $.69 * *$ & {$[.63, .75]$} & 2766.85 & .011 \\
\hline & Linear & $.08 * *$ & {$[.03, .13]$} & & & $.09 * *$ & {$[.03, .15]$} & & \\
\hline & Quadratic & & & & & -.02 & {$[-.05, .02]$} & & \\
\hline \multirow[t]{3}{*}{ Stress $\theta$} & Intercept & $.67 * *$ & {$[.62, .72]$} & 2767.04 & .005 & $.68 * *$ & {$[.62, .74]$} & 2773.32 & .005 \\
\hline & Linear & $.06^{*}$ & {$[.01, .11]$} & & & $.06^{*}$ & {$[.01, .12]$} & & \\
\hline & Quadratic & & & & & -.01 & {$[-.05, .03]$} & & \\
\hline \multirow[t]{3}{*}{$\mathrm{CH} \theta$} & Intercept & $.66^{* *}$ & {$[.61, .71]$} & 2745.05 & .028 & $.72 * *$ & {$[.66, .78]$} & 2741.83 & .037 \\
\hline & Linear & $.15^{* *}$ & {$[.09, .20]$} & & & $.14 * *$ & {$[.08, .20]$} & & \\
\hline & Quadratic & & & & & $-.06 * *$ & {$[-.12,-.01]$} & & \\
\hline
\end{tabular}

Note. PPI-R = Psychopathy Personality Inventory-Revised; SCI = Self-centered Impulsivity; BE = Blame Externalization; $\mathrm{CH}=$ Coldheartedness; $\mathrm{CN}=$ Carefree Nonplanfulness; $\mathrm{F}=$ Fearlessness; $\mathrm{FD}=$ Fearless Dominance; $\mathrm{ME}=$ Machiavellian Egocentricity; RN = Rebellious Nonconformity; Social = Social Influence; Stress = Stress Immunity; Bold text indicates the better model. Pseudo R2 value was calculated using McFadden's (1979) formula.

$* \mathrm{p}<.05 ; * \mathrm{p}<.01$ 
Table 2

Antisocial Behavior Regression Analyses

\begin{tabular}{|c|c|c|c|c|c|c|c|c|c|}
\hline \multirow[b]{2}{*}{ PPI-R Facet } & \multirow[b]{2}{*}{ Parameter } & \multicolumn{4}{|c|}{ Step 1} & \multicolumn{4}{|c|}{ Step 2} \\
\hline & & $B$ & {$[95 \% \mathrm{CI}]$} & $\mathrm{BIC}$ & Pseudo- $R 2$ & $B$ & {$[95 \% \mathrm{CI}]$} & $\mathrm{BIC}$ & Pseudo- $R 2$ \\
\hline \multirow[t]{3}{*}{ SCI Factor } & Intercept & $-.13 * *$ & {$[-.21,-.05]$} & 1994.35 & .036 & -.04 & {$[-.15, .06]$} & 1994.24 & .043 \\
\hline & Linear & $.31 * *$ & {$[.21, .41]$} & & & $.30 * *$ & {$[.19, .41]$} & & \\
\hline & Quadratic & & & & & $-.16^{*}$ & {$[-.29,-.03]$} & & \\
\hline \multirow[t]{3}{*}{ BE $\theta$} & Intercept & $-.12 * *$ & {$[-.19,-.04]$} & 2019.54 & .018 & -.05 & {$[-.15, .04]$} & 2021.33 & .023 \\
\hline & Linear & $.17 * *$ & {$[.09, .24]$} & & & $.15^{* *}$ & {$[.07, .24]$} & & \\
\hline & Quadratic & & & & & $-.07 *$ & {$[-.13,-.01]$} & & \\
\hline \multirow[t]{3}{*}{$\mathrm{CN} \theta$} & Intercept & $-.12 * *$ & {$[-.19,-.04]$} & 2016.91 & .017 & -.07 & {$[-.17, .04]$} & 2021.05 & .020 \\
\hline & Linear & $.16^{* *}$ & {$[.08, .24]$} & & & $.15^{* *}$ & {$[.07, .24]$} & & \\
\hline & Quadratic & & & & & -.05 & {$[-.12, .02]$} & & \\
\hline \multirow[t]{3}{*}{$\operatorname{ME} \theta$} & Intercept & $-.12 * *$ & {$[-.20,-.04]$} & 2006.73 & .027 & -.01 & {$[-.10, .07]$} & 1985.64 & .055 \\
\hline & Linear & $.20 * *$ & {$[.12, .27]$} & & & $.26^{* *}$ & {$[.17, .35]$} & & \\
\hline & Quadratic & & & & & $-.14 * *$ & {$[-.19,-.09]$} & & \\
\hline \multirow[t]{3}{*}{$\mathrm{RN} \theta$} & Intercept & $-.12 * *$ & {$[-.20,-.04]$} & 2007.22 & .023 & -.07 & {$[-.16, .03]$} & 2010.42 & .027 \\
\hline & Linear & $.19^{* *}$ & {$[.11, .26]$} & & & $.19^{* *}$ & {$[.11, .27]$} & & \\
\hline & Quadratic & & & & & -.06 & {$[-.12, .00]$} & & \\
\hline \multirow[t]{3}{*}{ FD Factor } & Intercept & $-.13 * *$ & {$[-.21,-.04]$} & 2001.94 & .032 & $-.11 *$ & {$[-.20,-.02]$} & 2007.91 & .033 \\
\hline & Linear & $.29 * *$ & {$[.20, .38]$} & & & $.31 * *$ & {$[.20, .43]$} & & \\
\hline & Quadratic & & & & & -.04 & {$[-.12, .05]$} & & \\
\hline \multirow[t]{3}{*}{$\mathrm{F} \theta$} & Intercept & $-.14 * *$ & {$[-.22,-.06]$} & 1980.28 & .054 & $-.10 *$ & {$[-.19,-.01]$} & 1982.71 & .058 \\
\hline & Linear & $.28 * *$ & {$[.21, .35]$} & & & $.31 * *$ & {$[.22, .39]$} & & \\
\hline & Quadratic & & & & & $-.05 *$ & {$[-.11, .00]$} & & \\
\hline Social $\theta$ & Intercept & $-.10^{*}$ & {$[-.18,-.02]$} & 2029.46 & .001 & $-.12 * *$ & {$[-.21,-.03]$} & 2035.23 & .002 \\
\hline Step 1 Disp. 4.91 & Linear & .04 & {$[-.03, .12]$} & & & .04 & {$[-.03, .11]$} & & \\
\hline Step 2 Disp. 4.95 & Quadratic & & & & & .02 & {$[-.02, .05]$} & & \\
\hline \multirow[t]{3}{*}{ Stress $\theta$} & Intercept & $-.11 * *$ & {$[-.19,-.03]$} & 2018.63 & .016 & $-.11 *$ & {$[-.2,-.02]$} & 2025.24 & .016 \\
\hline & Linear & $.15^{* *}$ & {$[.08, .22]$} & & & $.15^{* *}$ & {$[.07, .23]$} & & \\
\hline & Quadratic & & & & & -.01 & {$[-.05, .04]$} & & \\
\hline \multirow[t]{3}{*}{$\mathrm{CH} \theta$} & Intercept & $-.13 * *$ & {$[-.21,-.05]$} & 1994.40 & .043 & $-.10^{*}$ & {$[-.20, .00]$} & 1999.43 & .045 \\
\hline & Linear & $.26^{* *}$ & {$[.18, .33]$} & & & $.26 * *$ & {$[.18, .35]$} & & \\
\hline & Quadratic & & & & & -.04 & {$[-.11, .03]$} & & \\
\hline
\end{tabular}

Note. PPI-R = Psychopathy Personality Inventory-Revised; $\mathrm{BE}=$ Blame Externalization; $\mathrm{CH}=$ Coldheartedness; $\mathrm{CN}=\mathrm{Carefree}$ Nonplanfulness; Disp. $=$ Dispersion; $\mathrm{F}=$ Fearlessness; $\mathrm{ME}=$ Machiavellian Egocentricity; $\mathrm{RN}=$ Rebellious Nonconformity; Social = Social Influence; Stress = Stress Immunity. The smaller BIC values (in bold text) indicate the better fitting model. Pseudo R2 value was calculated using McFadden's (1979) formula.

$* \mathrm{p}<.05 ; * * \mathrm{p}<.01$ 
Table 3

$\underline{\text { Results of Regression Analysis for TriPM Facets and Externalizing Behavior }}$

\begin{tabular}{|c|c|c|c|c|c|c|c|c|c|}
\hline \multirow[b]{2}{*}{ TriPM Facet } & \multirow[b]{2}{*}{ Parameter } & \multicolumn{4}{|c|}{ Step 1} & \multicolumn{4}{|c|}{ Step 2} \\
\hline & & $B$ & {$[95 \% \mathrm{CI}]$} & $\mathrm{BIC}$ & Pseudo- $R^{2}$ & $B$ & {$[95 \% \mathrm{CI}]$} & $\mathrm{BIC}$ & Pseudo- $R^{2}$ \\
\hline \multicolumn{10}{|l|}{ Substance Use } \\
\hline \multirow[t]{3}{*}{ Boldness $\theta$} & Intercept & $.60 * *$ & {$[.53, .66]$} & 2043.00 & .001 & $.58 * *$ & {$[.51, .66]$} & 2048.56 & .002 \\
\hline & Linear & .02 & {$[-.05, .09]$} & & & .02 & {$[-.05, .08]$} & & \\
\hline & Quadratic & & & & & .02 & {$[-.03, .06]$} & & \\
\hline \multirow[t]{3}{*}{ Disinhibition $\theta$} & Intercept & $.58 * *$ & {$[.52, .64]$} & 2004.49 & .049 & $.55^{* *}$ & {$[.48, .62]$} & 2008.76 & .051 \\
\hline & Linear & $.19 * *$ & {$[.13, .26]$} & & & $.19 * *$ & {$[.12, .25]$} & & \\
\hline & Quadratic & & & & & .03 & {$[-.01, .07]$} & & \\
\hline \multirow[t]{3}{*}{ Meanness $\theta$} & Intercept & $.60 * *$ & {$[.53, .66]$} & 2041.10 & .003 & $.63^{* *}$ & {$[.54, .71]$} & 2046.11 & .005 \\
\hline & Linear & .05 & {$[-.02, .11]$} & & & .05 & {$[-.02, .11]$} & & \\
\hline & Quadratic & & & & & -.03 & {$[-.09, .03]$} & & \\
\hline \multicolumn{10}{|l|}{ Antisocial Behavior } \\
\hline Boldness $\theta$ & Intercept & .02 & {$[-.09, .12]$} & 1669.23 & .004 & -.04 & {$[-.15, .10]$} & 1673.69 & .007 \\
\hline Step 1 Disp. 1.53 & Linear & .08 & {$[-.03, .18]$} & & & .07 & {$[-.03, .16]$} & & \\
\hline Step 2 Disp. 1.55 & Quadratic & & & & & .04 & {$[-.01, .09]$} & & \\
\hline Disinhibition $\theta$ & Intercept & -.09 & {$[-.20, .01]$} & 1585.51 & .133 & $-.13 *$ & {$[-.24,-.01]$} & 1590.55 & .135 \\
\hline Step 1 Disp. 2.77 & Linear & $.48 * *$ & {$[.38, .58]$} & & & $.46^{* *}$ & {$[.35, .56]$} & & \\
\hline Step 2 Disp. 2.79 & Quadratic & & & & & .04 & {$[-.01, .09]$} & & \\
\hline Meanness $\theta$ & Intercept & -.01 & {$[-.12, .09]$} & 1648.00 & .038 & -.04 & {$[-.17, .10]$} & 1654.07 & .038 \\
\hline Step 1 Disp. 1.74 & Linear & $.25 * *$ & {$[.15, .35]$} & & & $.24 * *$ & {$[.14, .34]$} & & \\
\hline Step 2 Disp. 1.75 & Quadratic & & & & & -.02 & {$[-.06, .10]$} & & \\
\hline
\end{tabular}

Note. BIC values in bold text indicate a better fitting model based on Raftery's (1995) recommended threshold of BIC differences greater than two. Pseudo-R2 value was calculated using McFadden's (1974) formula.

$* \mathrm{p}<.05 ; * \mathrm{p}<.01$ 
Table 4

$\underline{\text { Results of Regression Analysis for TriPM Facets and Aggression }}$

\begin{tabular}{|c|c|c|c|c|c|c|c|c|c|}
\hline \multirow[b]{2}{*}{ TriPM Facet } & \multirow[b]{2}{*}{ Parameter } & \multicolumn{4}{|c|}{ Step 1} & \multicolumn{4}{|c|}{ Step 2} \\
\hline & & $B$ & {$[95 \% \mathrm{CI}]$} & $\mathrm{BIC}$ & $R^{2}$ & $B$ & {$[95 \% \mathrm{CI}]$} & $\mathrm{BIC}$ & $R^{2}$ \\
\hline \multicolumn{10}{|c|}{ Proactive Aggression } \\
\hline \multirow[t]{3}{*}{ Boldness $\theta$} & Intercept & .00 & {$[-.06, .06]$} & 1410.75 & .000 & .000 & {$[-.07, .07]$} & 1417.14 & .000 \\
\hline & Linear & -.01 & {$[-.07, .05]$} & & & -.01 & {$[-.07, .06]$} & & \\
\hline & Quadratic & & & & & .000 & {$[-.04, .04]$} & & \\
\hline \multirow[t]{3}{*}{ Disinhibition $\theta$} & Intercept & .00 & {$[-.06, .06]$} & 1268.83 & .213 & $-.13 * *$ & {$[-.19,-.06]$} & 1240.96 & .257 \\
\hline & Linear & $.36^{* *}$ & {$[.30, .42]$} & & & $.38 * *$ & {$[.32, .44]$} & & \\
\hline & Quadratic & & & & & $.13^{* *}$ & {$[.08, .17]$} & & \\
\hline \multirow[t]{3}{*}{ Meanness $\theta$} & Intercept & .00 & {$[-.06, .06]$} & 1303.87 & .165 & $-.14 * *$ & {$[-.21,-.06]$} & 1281.02 & .205 \\
\hline & Linear & $.32 * *$ & {$[.25, .38]$} & & & $.32 * *$ & {$[.26, .38]$} & & \\
\hline & Quadratic & & & & & $.14^{* *}$ & {$[.09, .19]$} & & \\
\hline \multicolumn{10}{|c|}{ Reactive Aggression } \\
\hline \multirow[t]{3}{*}{ Boldness $\theta$} & Intercept & .00 & {$[-.07, .07]$} & 1575.98 & .022 & -.04 & {$[-.12, .04]$} & 1579.35 & .027 \\
\hline & Linear & $-.13 * *$ & {$[-.21,-.06]$} & & & $-.14 * *$ & {$[-.22,-.07]$} & & \\
\hline & Quadratic & & & & & .04 & {$[.00, .08]$} & & \\
\hline \multirow[t]{3}{*}{ Disinhibition $\theta$} & Intercept & .00 & {$[-.06, .07]$} & 1448.48 & .211 & -.04 & {$[-.12, .05]$} & 1452.80 & .214 \\
\hline & Linear & $.42 * *$ & {$[.35, .48]$} & & & $.42 * *$ & {$[.35, .49]$} & & \\
\hline & Quadratic & & & & & .04 & {$[-.02, .09]$} & & \\
\hline \multirow[t]{3}{*}{ Meanness $\theta$} & Intercept & .00 & {$[-.07, .07]$} & 1565.14 & .040 & -.07 & {$[-.17, .03]$} & 1567.27 & .046 \\
\hline & Linear & $.18^{* *}$ & {$[.11, .26]$} & & & $.18^{* *}$ & {$[.11, .25]$} & & \\
\hline & Quadratic & & & & & .07 & {$[.00, .14]$} & & \\
\hline
\end{tabular}

Note. TriPM $=$ Triarchic Psychopathy Measure. BIC values in bold text indicate a better fitting model based on Raftery's (1995) recommended threshold of BIC differences greater than two. $\mathrm{R}^{2}$ values in negative binomial models are Pseudo- $\mathrm{R}^{2}$ values calculated using McFadden's (1974) formula.

$* \mathrm{p}<.05 ; * * \mathrm{p}<.01$ 
Supplemental Table 1

Psychopathy Scale Correlations in Samples 1 and 2

\begin{tabular}{lccccccccc} 
Sample 1 (PPI-R) & 1 & 2 & 3 & 4 & 5 & 6 & 7 & 8 & 9 \\
1. Self-centered Impulsivity & & & & & & & & & \\
2. Blame Externalization & $.75^{*}$ & & & & & & & & \\
3. Carefree Nonplanfulness & $.78^{*}$ & $.46^{*}$ & & & & & & & \\
4. Machiavellian Egocentricity & $.79^{*}$ & $.50^{*}$ & $.41^{*}$ & & & & & & \\
5. Rebellious Nonconformity & $.77^{*}$ & $.40^{*}$ & $.49^{*}$ & $.51^{*}$ & & & & & \\
6. Fearless Dominance & $.11^{*}$ & $-.16^{*}$ & .01 & $.17^{*}$ & $.31^{*}$ & & & & \\
7. Fearlessness & $.35^{*}$ & .08 & $.21^{*}$ & $.29^{*}$ & $.50^{*}$ & $.76^{*}$ & & & \\
8. Social Influence & -.02 & $-.17^{*}$ & -.15 & $.14^{*}$ & $.11^{*}$ & $.72^{*}$ & $.27^{*}$ & & \\
$\quad$ 9. Stress Immunity & $-.16^{*}$ & $-.32^{*}$ & -.07 & $-.11^{*}$ & .00 & $.69^{*}$ & $.33^{*}$ & $.29 *$ \\
10. Coldheartedness & $.49^{*}$ & $.26^{*}$ & $.50^{*}$ & $.47^{*}$ & $.26^{*}$ & $.22^{*}$ & $.22^{*}$ & .02 & $.25^{*}$ \\
Sample 2 (TriPM) & & & & & & & & & \\
1. Boldness & 1 & 2 & & & & & & & \\
2. Disinhibition & & & & & & & & & \\
3. Meanness & $-.26^{*}$ & & & & & & & & \\
\hline
\end{tabular}

Note. PPI-R = Psychopathic Personality Inventory-Revised. TriPM = Triarchic Psychopathy Measure. Indented scale names indicate they are facets of the above factor.

$* p<.01$ 
Supplemental Table 2

GPCM Model-Data Fit Adjusted (to $\mathrm{N}=3,000) \chi^{2} / \mathrm{df}$ Ratios from MODFIT 2.0 (Stark, 2007)

\begin{tabular}{|c|c|c|c|c|c|c|c|c|c|c|}
\hline & Statistic & $<1$ & $1<2$ & $2<3$ & $3<4$ & $4<5$ & $5<7$ & $>7$ & Mean & $S D$ \\
\hline \multicolumn{11}{|l|}{ Sample 1} \\
\hline \multirow[t]{3}{*}{$\mathrm{BE}$} & Singlets & 15 & 0 & 0 & 0 & 0 & 0 & 0 & 0.00 & 0.00 \\
\hline & Doublets & 0 & 1 & 1 & 0 & 0 & 1 & 12 & 10.93 & 6.27 \\
\hline & Triplets & 0 & 0 & 0 & 0 & 0 & 2 & 3 & 9.12 & 3.03 \\
\hline \multirow[t]{3}{*}{$\mathrm{CN}$} & Singlets & 19 & 0 & 0 & 0 & 0 & 0 & 0 & 0.00 & 0.00 \\
\hline & Doublets & 4 & 1 & 0 & 1 & 1 & 6 & 8 & 6.25 & 4.45 \\
\hline & Triplets & 1 & 0 & 0 & 1 & 1 & 2 & 4 & 5.94 & 2.67 \\
\hline \multirow[t]{3}{*}{$\mathrm{C}$} & Singlets & 16 & 0 & 0 & 0 & 0 & 0 & 0 & 0.00 & 0.00 \\
\hline & Doublets & 2 & 2 & 1 & 2 & 5 & 3 & 3 & 4.33 & 2.69 \\
\hline & Triplets & 0 & 0 & 2 & 2 & 2 & 2 & 0 & 3.84 & 1.27 \\
\hline \multirow[t]{3}{*}{$\mathrm{F}$} & Singlets & 14 & 0 & 0 & 0 & 0 & 0 & 0 & 0.00 & 0.00 \\
\hline & Doublets & 1 & 1 & 1 & 2 & 2 & 5 & 6 & 7.57 & 5.22 \\
\hline & Triplets & 0 & 0 & 2 & 1 & 0 & 3 & 4 & 5.97 & 2.34 \\
\hline \multirow[t]{3}{*}{$\mathrm{ME}$} & Singlets & 20 & 0 & 0 & 0 & 0 & 0 & 0 & 0.00 & 0.00 \\
\hline & Doublets & 2 & 1 & 7 & 4 & 4 & 3 & 3 & 4.39 & 3.31 \\
\hline & Triplets & 0 & 2 & 2 & 5 & 2 & 0 & 1 & 3.71 & 1.80 \\
\hline \multirow[t]{3}{*}{$\mathrm{R}$} & Singlets & 16 & 0 & 0 & 0 & 0 & 0 & 0 & 0.00 & 0.00 \\
\hline & Doublets & 1 & 0 & 2 & 1 & 0 & 4 & 10 & 7.01 & 3.24 \\
\hline & Triplets & 0 & 0 & 1 & 1 & 0 & 5 & 1 & 5.41 & 1.62 \\
\hline \multirow[t]{3}{*}{ Social } & Singlets & 18 & 0 & 0 & 0 & 0 & 0 & 0 & 0.00 & 0.00 \\
\hline & Doublets & 0 & 2 & 0 & 4 & 0 & 1 & 11 & 8.60 & 5.30 \\
\hline & Triplets & 0 & 0 & 0 & 2 & 0 & 2 & 2 & 6.44 & 2.96 \\
\hline \multirow[t]{3}{*}{ Stress } & Singlets & 13 & 0 & 0 & 0 & 0 & 0 & 0 & 0.00 & 0.00 \\
\hline & Doublets & 0 & 0 & 0 & 0 & 2 & 6 & 7 & 9.72 & 6.40 \\
\hline & Triplets & 0 & 0 & 0 & 1 & 2 & 2 & 2 & 6.65 & 4.00 \\
\hline \multicolumn{11}{|l|}{ Sample 2} \\
\hline \multirow[t]{3}{*}{$\mathrm{B}$} & Singlets & 19 & 0 & 0 & 0 & 0 & 0 & 0 & 0.00 & 0.00 \\
\hline & Doublets & 5 & 4 & 1 & 4 & 2 & 3 & 2 & 3.09 & 2.58 \\
\hline & Triplets & 1 & 2 & 3 & 1 & 1 & 1 & 0 & 2.62 & 1.68 \\
\hline \multirow[t]{3}{*}{ D } & Singlets & 20 & 0 & 0 & 0 & 0 & 0 & 0 & 0.00 & 0.00 \\
\hline & Doublets & 9 & 4 & 3 & 1 & 0 & 3 & 4 & 3.30 & 4.35 \\
\hline & Triplets & 1 & 5 & 1 & 1 & 3 & 0 & 1 & 3.16 & 3.02 \\
\hline \multirow[t]{3}{*}{ M } & Singlets & 18 & 0 & 0 & 0 & 0 & 0 & 0 & 0.00 & 0.00 \\
\hline & Doublets & 8 & 1 & 1 & 2 & 1 & 2 & 3 & 3.99 & 6.43 \\
\hline & $\underline{\text { Triplets }}$ & 0 & 0 & 3 & 1 & 0 & 1 & 1 & 4.89 & 4.29 \\
\hline \multirow[t]{3}{*}{ Proactive } & Singlets & 12 & 0 & 0 & 0 & 0 & 0 & 0 & 0.00 & 0.00 \\
\hline & Doublets & 12 & 0 & 0 & 0 & 0 & 0 & 0 & 0.00 & 0.00 \\
\hline & Triplets & 4 & 0 & 0 & 0 & 0 & 0 & 0 & 0.00 & 0.00 \\
\hline \multirow[t]{3}{*}{ Reactive } & Singlets & 11 & 0 & 0 & 0 & 0 & 0 & 0 & 0.00 & 0.00 \\
\hline & Doublets & 7 & 0 & 0 & 1 & 2 & 1 & 4 & 4.54 & 5.98 \\
\hline & Triplets & 0 & 1 & 2 & 0 & 1 & 2 & 3 & 6.32 & 5.13 \\
\hline
\end{tabular}

Note. $\mathrm{BE}=$ Blame Externalization; $\mathrm{CN}=$ Carefree Nonplanfulness; $\mathrm{C}=$ Coldheartedness; $\mathrm{F}=$ Fearlessness; $\mathrm{ME}=$ Machiavellian Egocentricity; RN = Rebellious Nonconformity; Social = Social Influence; Stress = Stress Immunity; $\mathrm{B}=$ Boldness; $\mathrm{D}=$ Disinhibition; $\mathrm{M}=$ Meanness Proactive $=$ Proactive Aggression; Reactive $=$ Reactive Aggression. 
Supplemental Table 3

GGUM Model-Data Fit Adjusted (to $\mathrm{N}=3,000) \chi 2 /$ df Ratios from MODFIT 2.0 (Stark, 2007)

\begin{tabular}{|c|c|c|c|c|c|c|c|c|c|c|}
\hline & Statistic & $<1$ & $1<2$ & $2<3$ & $3<4$ & $4<5$ & $5<7$ & $>7$ & Mean & SD \\
\hline \multicolumn{11}{|l|}{ Sample 1} \\
\hline \multirow[t]{3}{*}{$\mathrm{BE}$} & Singlets & 15 & 0 & 0 & 0 & 0 & 0 & 0 & 0.00 & 0.00 \\
\hline & Doublets & 0 & 1 & 1 & 0 & 0 & 3 & 10 & 9.11 & 4.53 \\
\hline & $\underline{\text { Triplets }}$ & 0 & 0 & 0 & 0 & 0 & 3 & 2 & 7.66 & 2.25 \\
\hline \multirow[t]{3}{*}{$\mathrm{CN}$} & Singlets & 19 & 0 & 0 & 0 & 0 & 0 & 0 & 0.00 & 0.00 \\
\hline & Doublets & 0 & 2 & 1 & 2 & 1 & 6 & 9 & 7.02 & 3.88 \\
\hline & Triplets & 1 & 3 & 0 & 2 & 1 & 1 & 1 & 3.57 & 2.60 \\
\hline \multirow[t]{3}{*}{$\mathrm{C}$} & Singlets & 16 & 0 & 0 & 0 & 0 & 0 & 0 & 0.00 & 0.00 \\
\hline & Doublets & 1 & 1 & 1 & 0 & 4 & 2 & 9 & 6.61 & 3.40 \\
\hline & Triplets & 0 & 1 & 0 & 1 & 1 & 4 & 1 & 5.11 & 1.91 \\
\hline \multirow[t]{3}{*}{$\mathrm{F}$} & Singlets & 14 & 0 & 0 & 0 & 0 & 0 & 0 & 0.00 & 0.00 \\
\hline & Doublets & 0 & 0 & 1 & 1 & 2 & 2 & 12 & 9.00 & 3.94 \\
\hline & Triplets & 0 & 0 & 0 & 1 & 0 & 3 & 6 & 7.32 & 2.28 \\
\hline \multirow[t]{3}{*}{$\mathrm{ME}$} & Singlets & 20 & 0 & 0 & 0 & 0 & 0 & 0 & 0.00 & 0.00 \\
\hline & Doublets & 3 & 2 & 2 & 4 & 7 & 2 & 4 & 4.41 & 2.93 \\
\hline & Triplets & 0 & 2 & 3 & 3 & 1 & 1 & 2 & 3.98 & 2.11 \\
\hline \multirow[t]{3}{*}{$\mathrm{R}$} & Singlets & 16 & 0 & 0 & 0 & 0 & 0 & 0 & 0.00 & 0.00 \\
\hline & Doublets & 3 & 1 & 0 & 1 & 4 & 4 & 5 & 5.15 & 3.21 \\
\hline & Triplets & 0 & 0 & 2 & 0 & 3 & 3 & 0 & 4.30 & 1.50 \\
\hline \multirow[t]{3}{*}{ Social } & Singlets & 16 & 2 & 0 & 0 & 0 & 0 & 0 & 0.14 & 0.41 \\
\hline & Doublets & 0 & 2 & 0 & 0 & 1 & 0 & 15 & 12.01 & 7.03 \\
\hline & Triplets & 0 & 0 & 1 & 0 & 0 & 1 & 4 & 7.74 & 3.25 \\
\hline \multirow[t]{3}{*}{ Stress } & Singlets & 13 & 0 & 0 & 0 & 0 & 0 & 0 & 0.00 & 0.00 \\
\hline & Doublets & 1 & 0 & 0 & 1 & 3 & 4 & 6 & 8.25 & 5.30 \\
\hline & Triplets & 0 & 1 & 0 & 1 & 1 & 3 & 1 & 5.03 & 2.43 \\
\hline \multicolumn{11}{|l|}{ Sample 2} \\
\hline \multirow[t]{3}{*}{ B } & Singlets & 19 & 0 & 0 & 0 & 0 & 0 & 0 & 0.00 & 0.00 \\
\hline & Doublets & 3 & 1 & 4 & 4 & 2 & 3 & 4 & 4.43 & 3.37 \\
\hline & Triplets & 0 & 0 & 1 & 3 & 2 & 1 & 2 & 5.03 & 2.73 \\
\hline \multirow[t]{3}{*}{ D } & Singlets & 20 & 0 & 0 & 0 & 0 & 0 & 0 & 0.00 & 0.00 \\
\hline & Doublets & 3 & 6 & 5 & 2 & 4 & 0 & 4 & 4.16 & 4.88 \\
\hline & Triplets & 0 & 1 & 5 & 0 & 1 & 3 & 2 & 4.51 & 2.61 \\
\hline \multirow[t]{3}{*}{ M } & Singlets & 18 & 0 & 0 & 0 & 0 & 0 & 0 & 0.00 & 0.00 \\
\hline & Doublets & 8 & 2 & 2 & 0 & 0 & 3 & 3 & 3.89 & 6.42 \\
\hline & Triplets & 1 & 0 & 2 & 0 & 1 & 1 & 1 & 4.73 & 4.69 \\
\hline \multirow[t]{3}{*}{ Proactive } & Singlets & 12 & 0 & 0 & 0 & 0 & 0 & 0 & 0.00 & 0.00 \\
\hline & Doublets & 12 & 0 & 0 & 0 & 0 & 0 & 0 & 0.00 & 0.00 \\
\hline & Triplets & 4 & 0 & 0 & 0 & 0 & 0 & 0 & 0.00 & 0.00 \\
\hline \multirow[t]{3}{*}{ Reactive } & Singlets & 11 & 0 & 0 & 0 & 0 & 0 & 0 & 0.00 & 0.00 \\
\hline & Doublets & 7 & 0 & 0 & 3 & 0 & 2 & 3 & 4.11 & 5.56 \\
\hline & Triplets & 0 & 2 & 1 & 1 & 0 & 3 & 2 & 5.73 & 4.54 \\
\hline
\end{tabular}

Note. $\mathrm{BE}=$ Blame Externalization; $\mathrm{CN}=$ Carefree Nonplanfulness; $\mathrm{C}=$ Coldheartedness; $\mathrm{F}=$ Fearlessness; $\mathrm{ME}=$ Machiavellian Egocentricity; RN = Rebellious Nonconformity; Social = Social Influence; Stress = Stress Immunity; $\mathrm{B}=$ Boldness; $\mathrm{D}=$ Disinhibition; $\mathrm{M}=$ Meanness. Proactive $=$ Proactive Aggression; Reactive $=$ Reactive Aggression. 
Supplemental Table 4

Relative Model-Data Fit (AIC) of GPCM and GGUM Models

GPCM GGUM AIC $\Delta$

Sample 1

$\begin{array}{llll}\text { Blame Externalization } & 24212 & 24083 & 129\end{array}$

Carefree Nonplanfulness $\quad 30545 \quad 30312 \quad 234$

$\begin{array}{llll}\text { Coldheartedness } & 26617 & 26462 & 155\end{array}$

$\begin{array}{llll}\text { Fearlessness } & 25941 & 25787 & 154\end{array}$

Machiavellian Egocentricity $\quad 34720 \quad 34441 \quad 279$

Rebellious Nonconformity $27383 \quad 27111 \quad 272$

Social Influence $\quad 31356 \quad 31000 \quad 356$

Stress Immunity $22571 \quad 22365 \quad 205$

Sample 2

Boldness $\quad 25930 \quad 25965 \quad-35$

Disinhibition $\quad 21158 \quad 21191 \quad-33$

$\begin{array}{llll}\text { Meanness } & 17324 & 17343 & -19\end{array}$

Proactive Aggression $\quad 4365 \quad 4383 \quad-18$

$\begin{array}{llll}\text { Reactive Aggression } & 9201 & 9262 & -61\end{array}$

Note: $\mathrm{AIC}=$ Akaike Information Criterion 


\section{Supplemental Table 5}

Descriptive Statistics and Extreme Responses for Estimated Scales

\begin{tabular}{llcccccc}
\hline & & & & Max & \# High \\
Sample 1 & Scale & $M$ & $S D$ & Med. & Raw & Max $\theta$ & Resp. \\
\cline { 2 - 7 } N=787 & BE & 15.22 & 6.99 & 16 & $41 / 45$ & 3.13 & 16 \\
& CN & 18.76 & 8.35 & 18 & $45 / 57$ & 1.94 & 9 \\
& CH & 16.68 & 7.37 & 17 & $46 / 48$ & 3.21 & 22 \\
& F & 19.24 & 8.23 & 20 & $41 / 42$ & 2.89 & 134 \\
& ME & 22.92 & 8.14 & 23 & $51 / 60$ & 3.26 & 31 \\
& RN & 16.60 & 7.48 & 17 & $40 / 48$ & 2.96 & 33 \\
& Social & 28.88 & 7.78 & 29 & $52 / 54$ & 3.87 & 202 \\
Sample 2 & Stress & 20.79 & 6.24 & 21 & $39 / 39$ & 3.04 & 221 \\
N=596 & Boldness & 48.01 & 9.74 & 48 & $76 / 76$ & 3.3 & 113 \\
& Meanness & 28.39 & 7.99 & 26 & $65 / 72$ & 3.09 & 3 \\
& Disinhibition & 35.13 & 9.09 & 34 & $77 / 80$ & 3.26 & 10 \\
& Proactive & 1.52 & 2.44 & 1 & $20 / 24$ & 3.19 & 11 \\
& Reactive & 6.85 & 3.66 & 7 & $22 / 22$ & 3.41 & 128 \\
\hline
\end{tabular}

Note. \# High Responders $=$ number of individuals in the sample that endorsed at least $3 / 4$ of the items in the scale; $\mathrm{BE}=$ Blame Externalization; $\mathrm{CH}=$ Coldheartedness; $\mathrm{CN}=$ Carefree Nonplanfulness; F = Fearlessness; FD = Fearless Dominance; Max Raw $=$ maximum observed raw response score after accounting for reverse scored items, denominator represents the highest possible raw score; $\operatorname{Max} \theta=$ largest estimated latent trait score; $\mathrm{ME}=$ Machiavellian Egocentricity; Med. = Median raw score; Proactive $=$ Proactive Aggression; Reactive $=$ Reactive Aggression; $\mathrm{RN}=$ Rebellious Nonconformity; Social $=$ Social Influence; Stress $=$ Stress Immunity . 


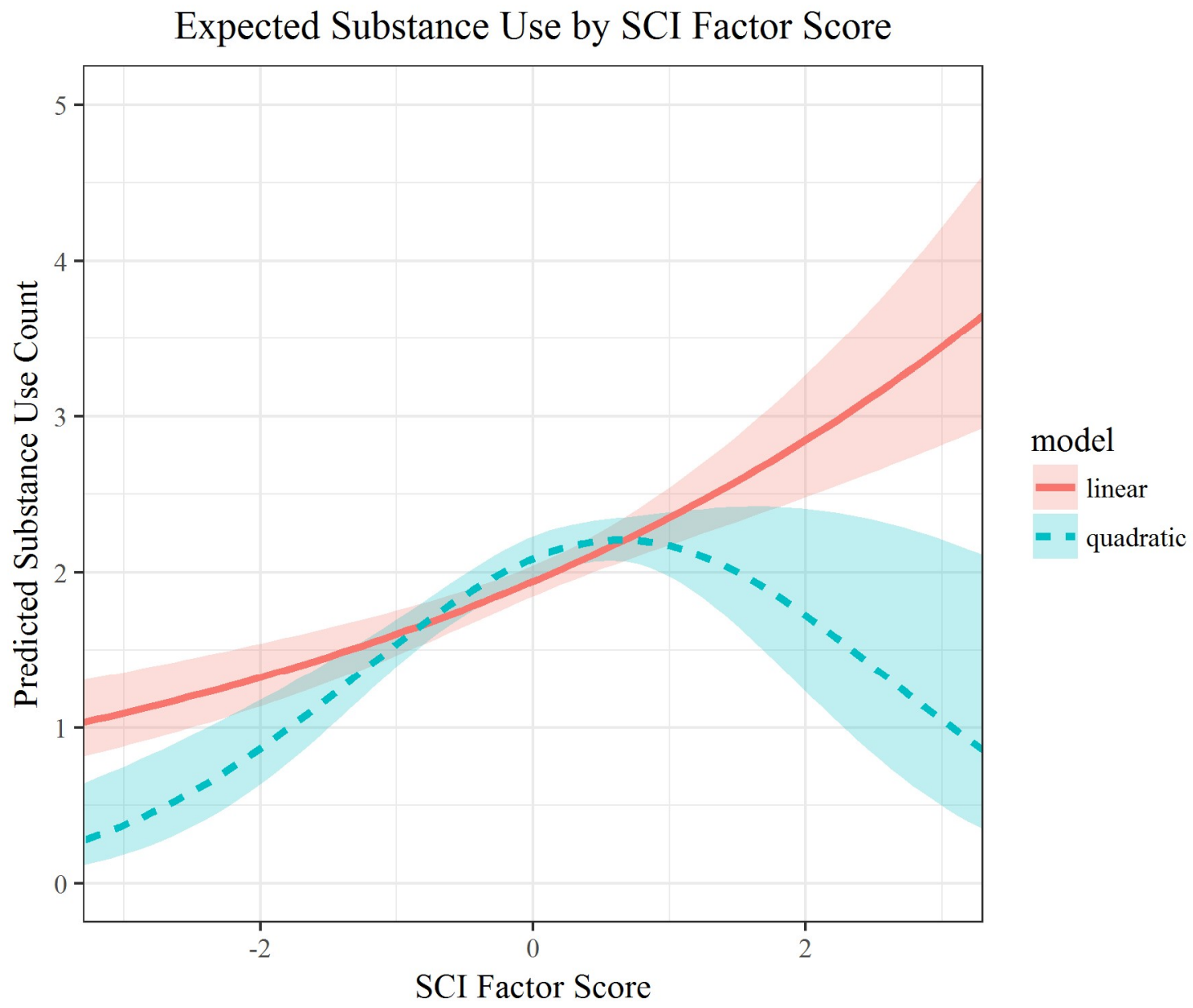

Supplemental Figure 1. Predicting Substance Use Count by SCI factor score in Sample 1. Ribbons around the lines represent $95 \%$ confidence intervals. 


\section{Expected Substance Use by Machiavellian Egocentricity}

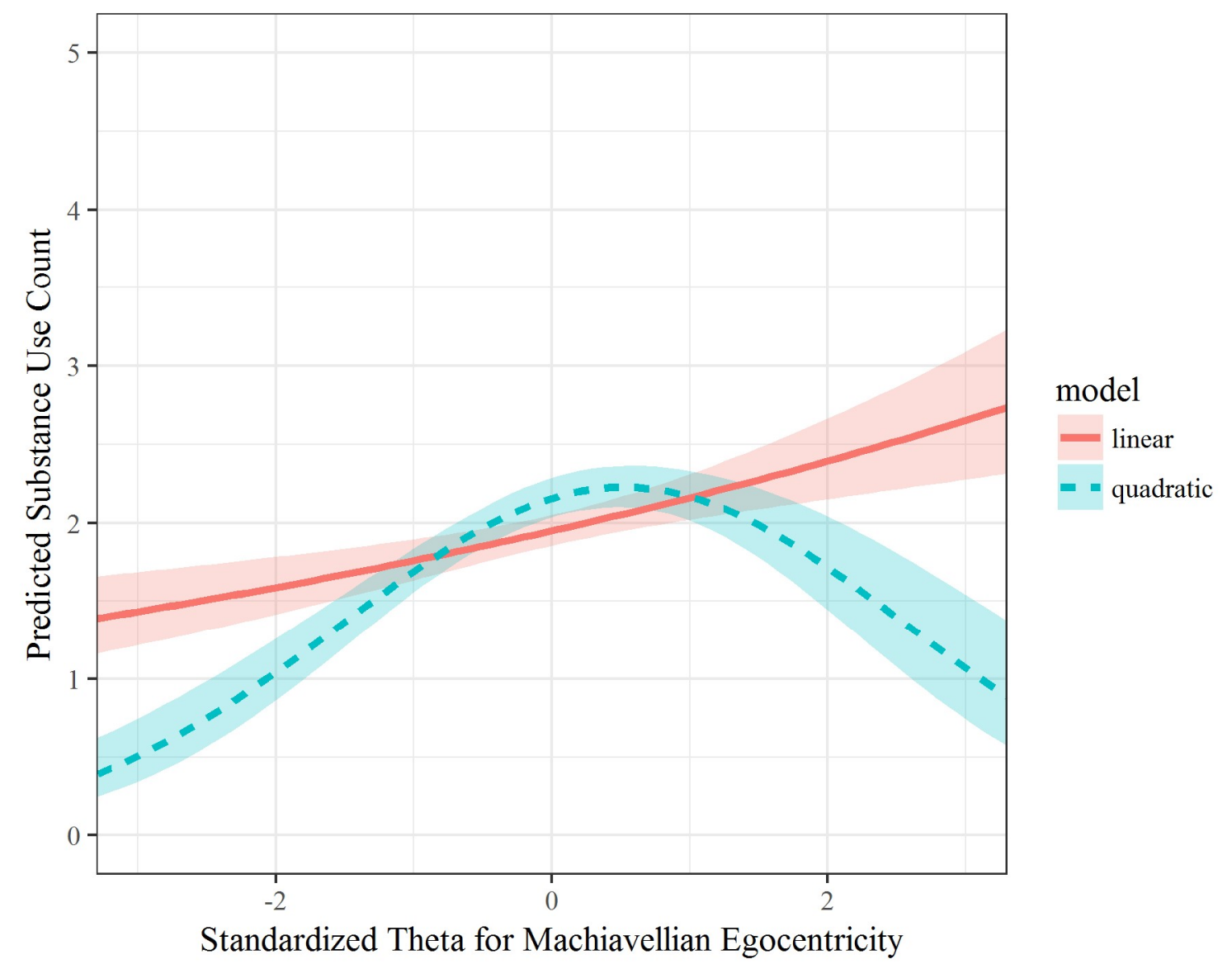

Supplemental Figure 2. Predicting Substance Use Count by Machiavellian Egocentricity in Sample 1 . Ribbons around the lines represent $95 \%$ confidence intervals. 


\section{Expected Substance Use by Rebellious Nonconformity}

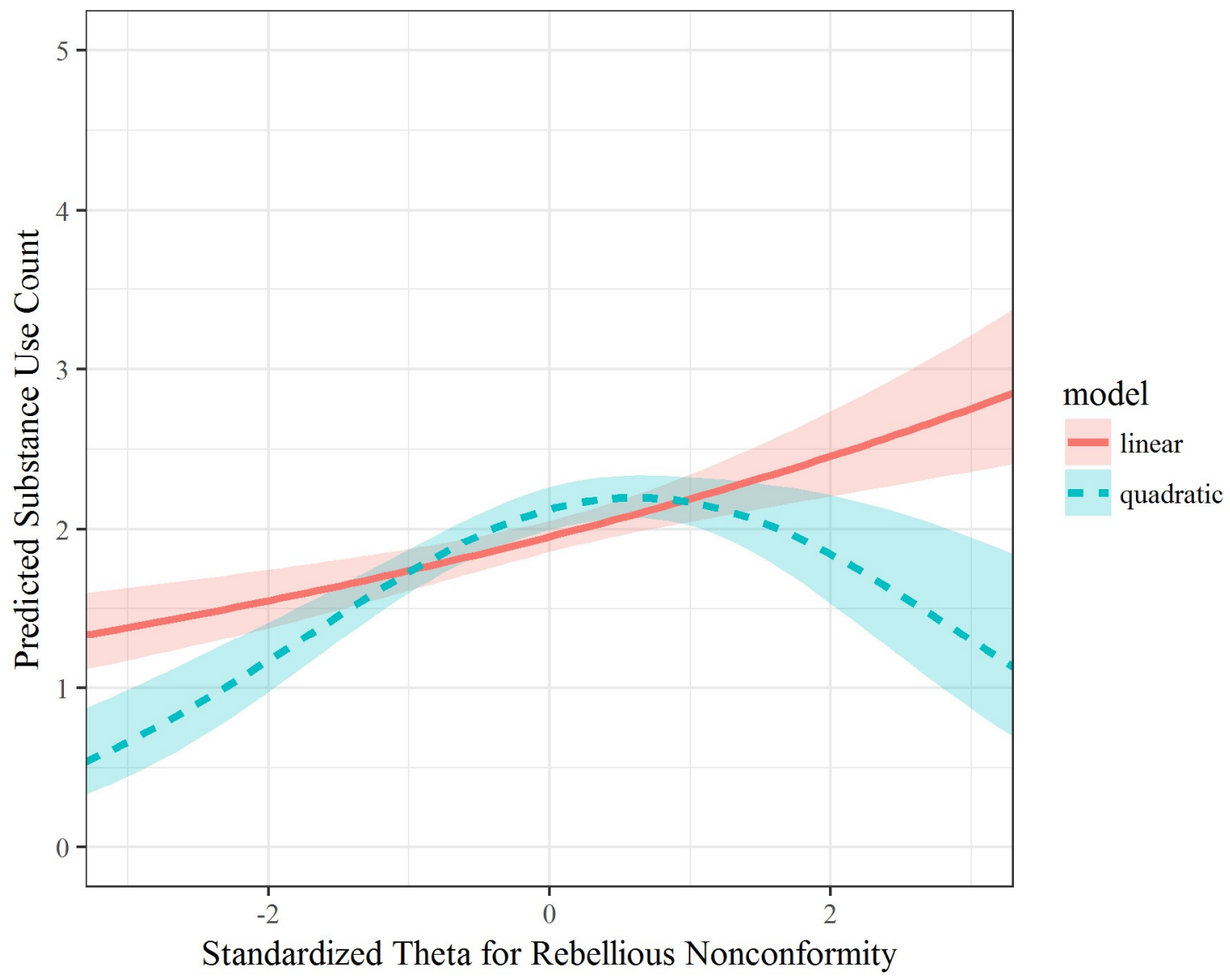

Supplemental Figure 3. Predicting Substance Use Count by Rebellious Nonconformity in Sample 1 . Ribbons around the lines represent $95 \%$ confidence intervals. 


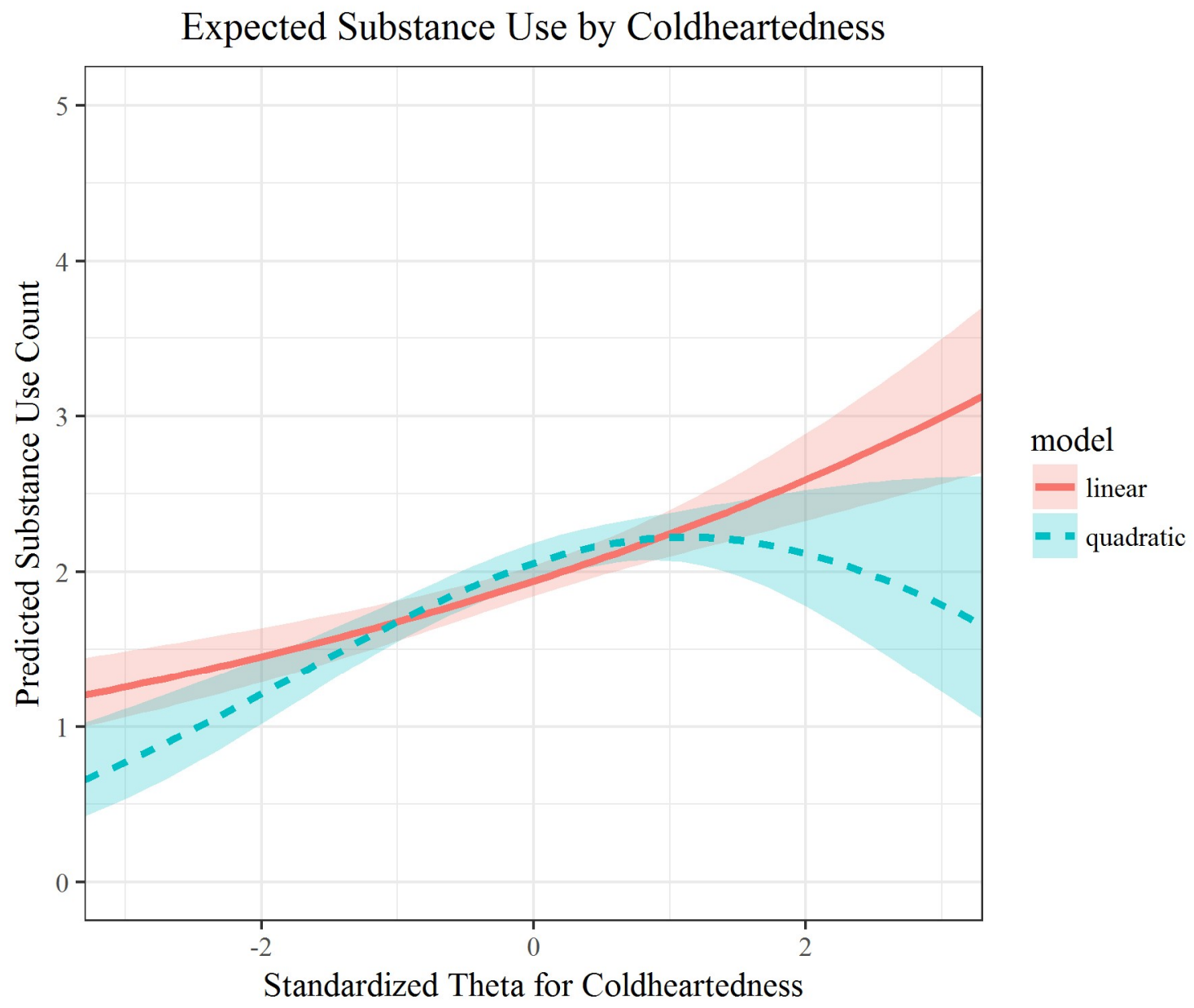

Supplemental Figure 4. Predicting Substance Use Count by Coldheartedness in Sample 1. Ribbons around the lines represent 95\% confidence intervals. 
Expected Antisocial Behavior by Machiavellian Egocentricity

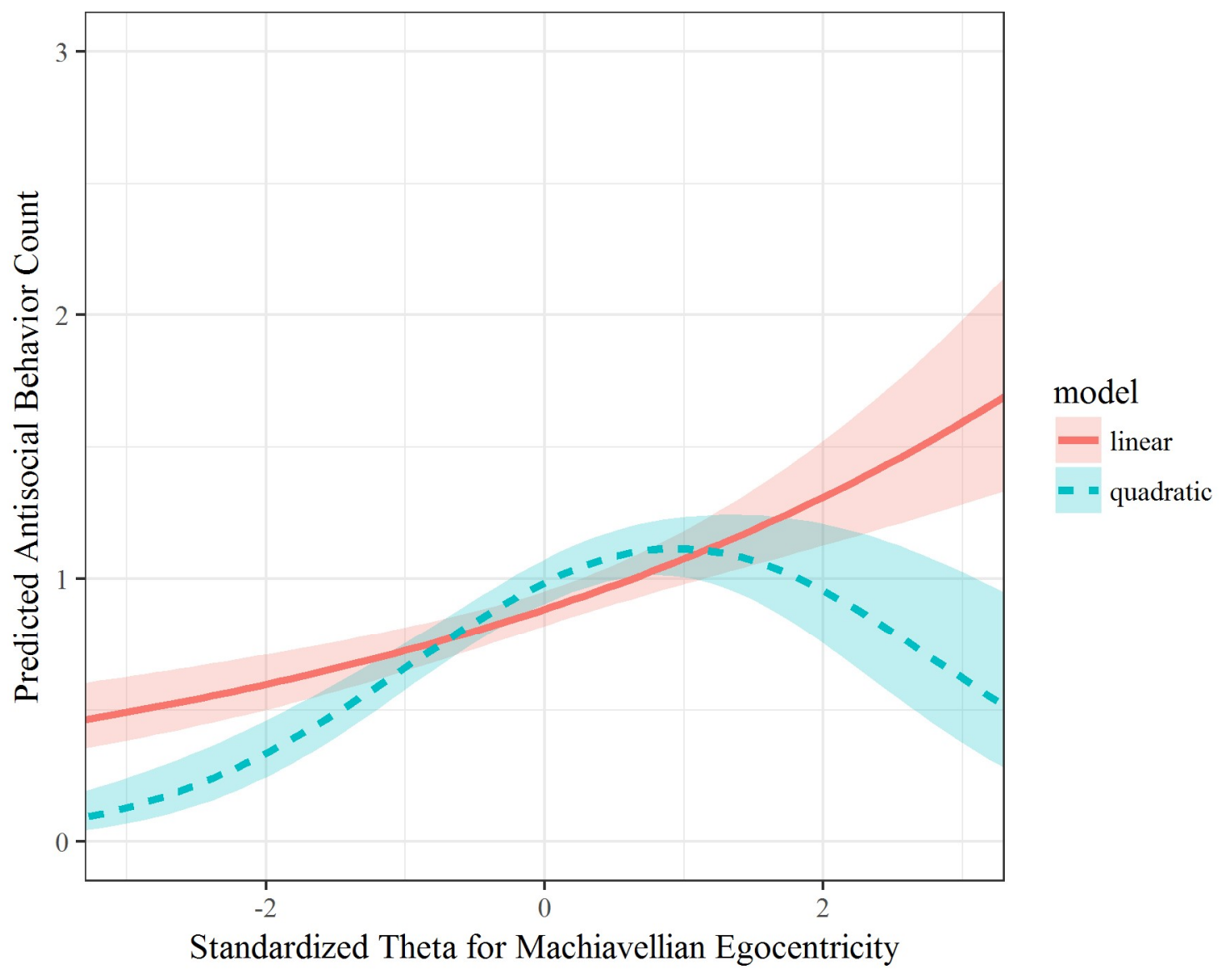

Supplemental Figure 5. Predicting Antisocial Behavior Count by Machiavellian Egocentricity in Sample 1. Ribbons around the lines represent $95 \%$ confidence intervals. 


\section{Expected Proactive Aggression Theta by Meanness}

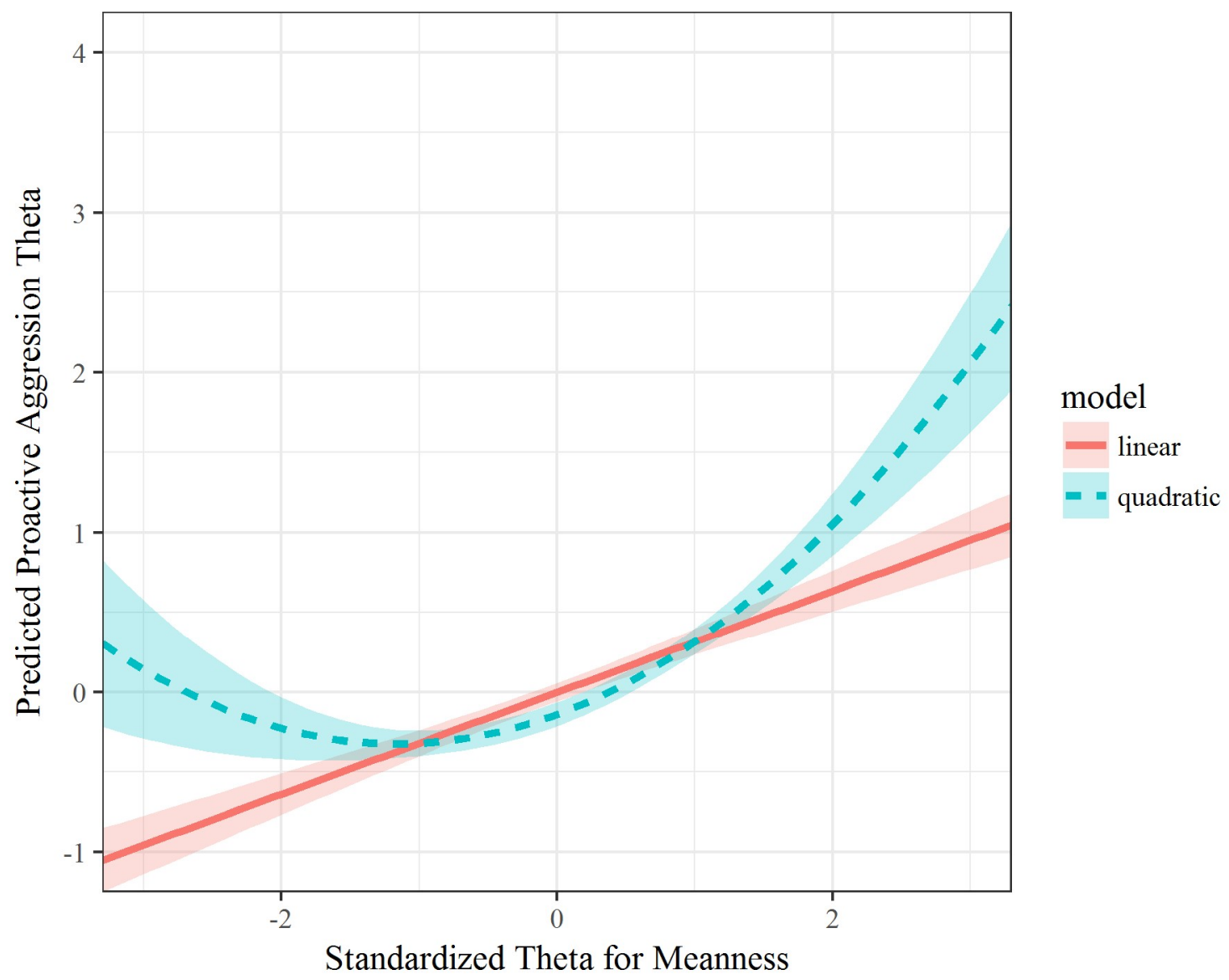

Supplemental Figure 6. Predicting proactive aggression by Meanness in Sample 2. Ribbons around the lines represent $95 \%$ confidence intervals. 


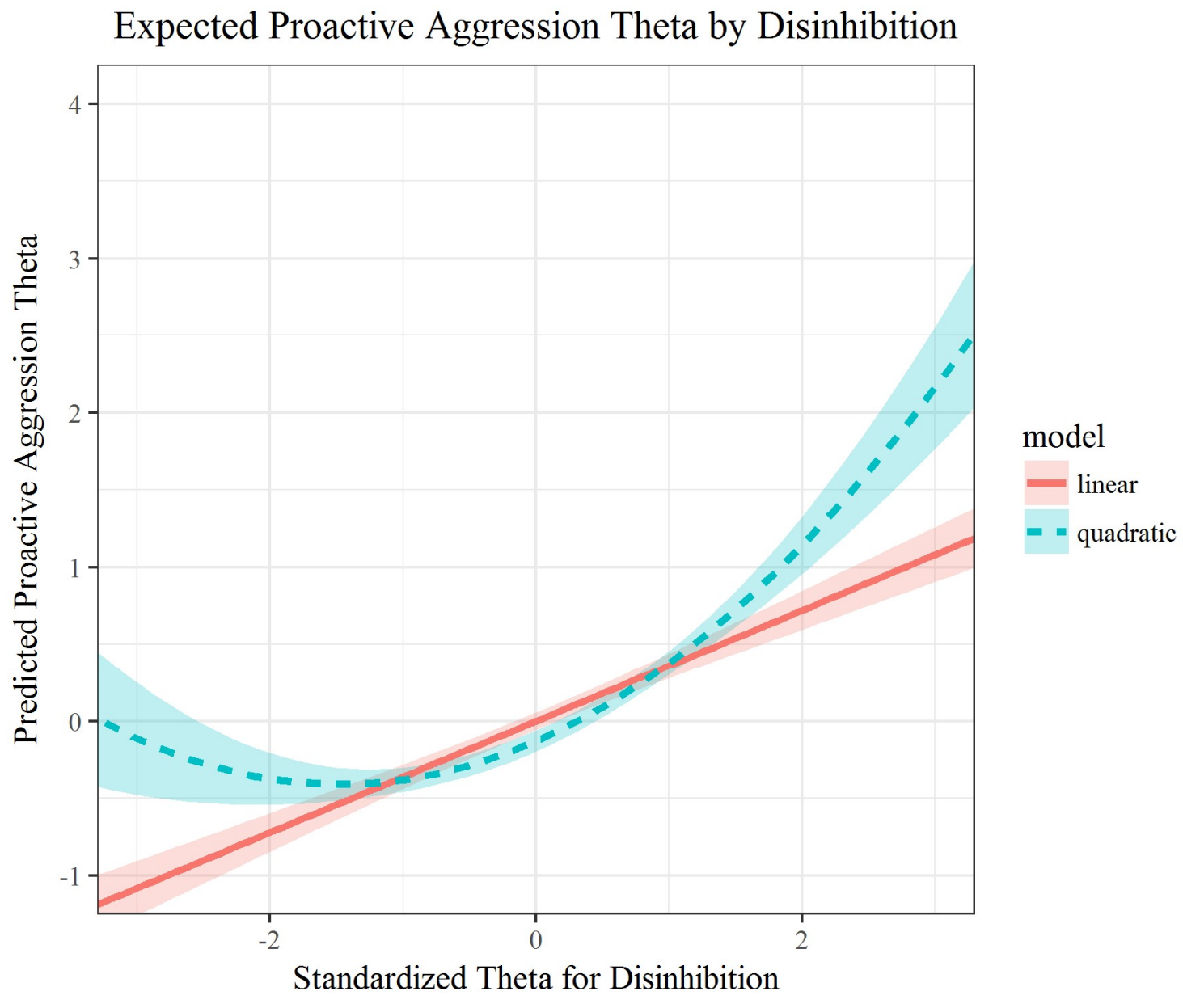

Supplemental Figure 7. Predicting proactive aggression by Disinhibition in Sample 2. Ribbons around the lines represent $95 \%$ confidence intervals. 
Test Reliability Functions for Self-centered Impulsivity Scales

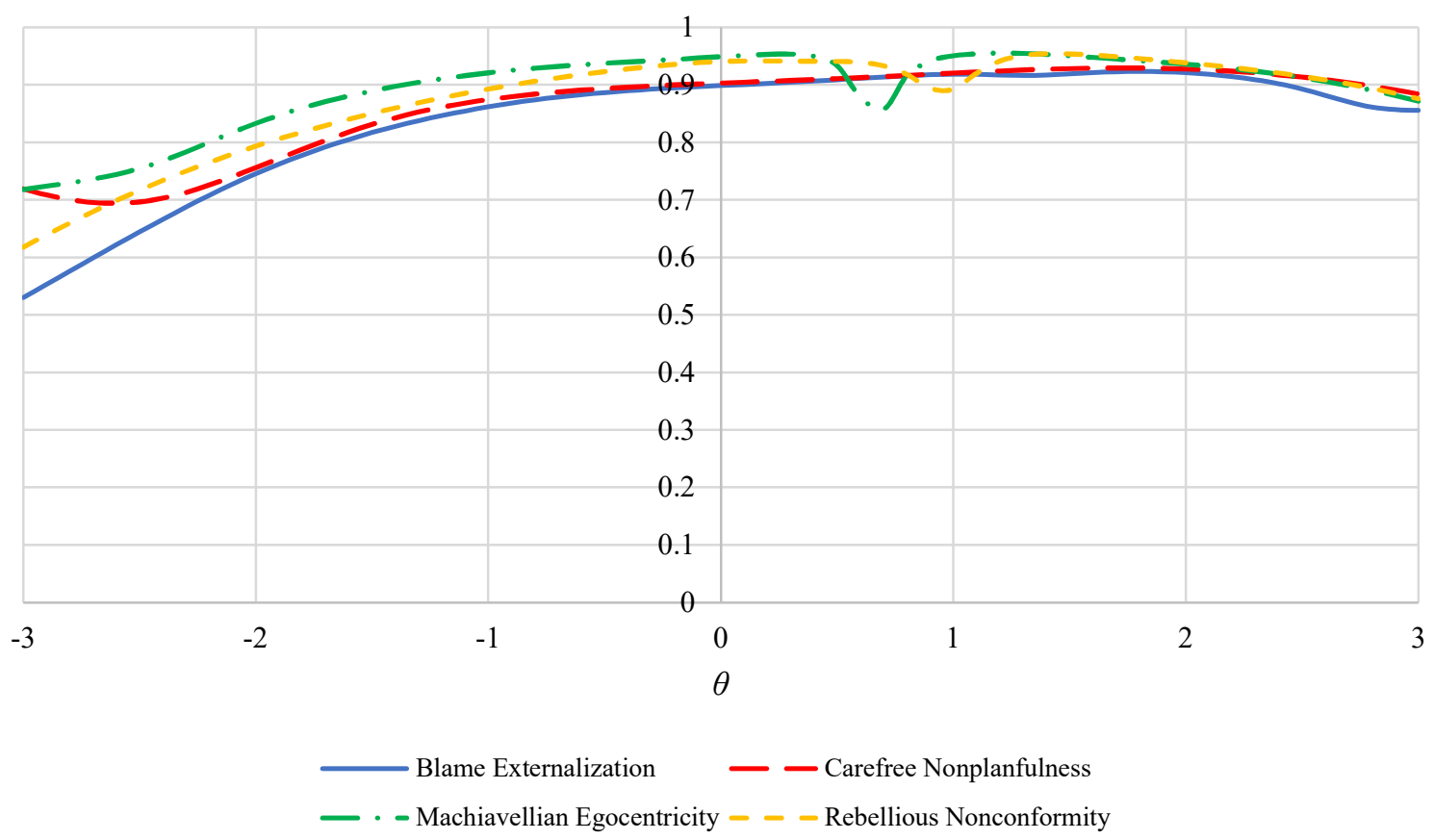

Supplemental Figure 8. Sample 1 test reliability functions for PPI-R Self-centered Impulsivity scales estimated using GGUM. 
Test Reliability Functions for Fearless Dominance Scales

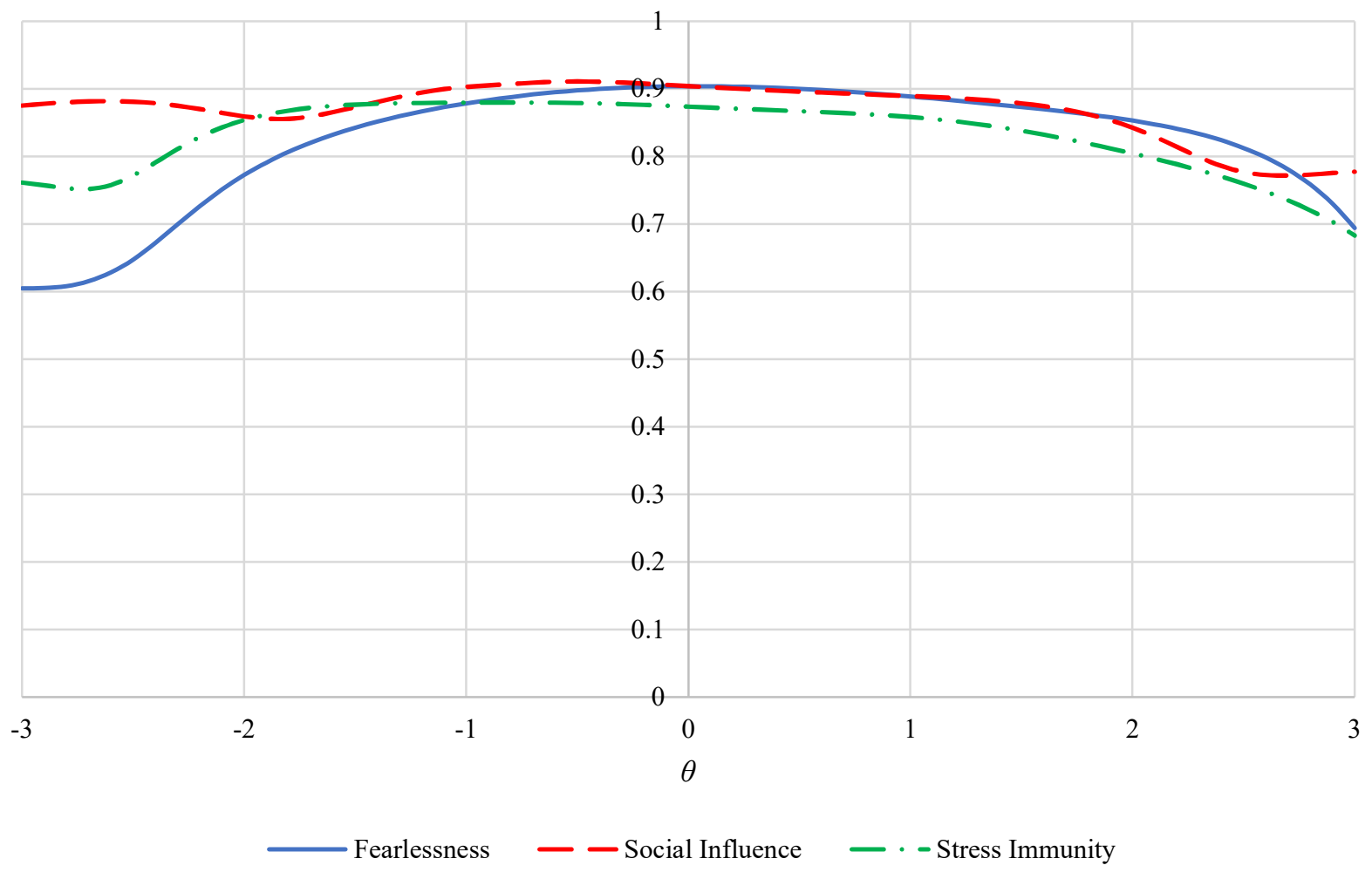

Supplemental Figure 9. Sample 1 test reliability functions for PPI-R Fearless Dominance scales estimated using GGUM. 


\section{Test Reliability Function for Coldheartedness}

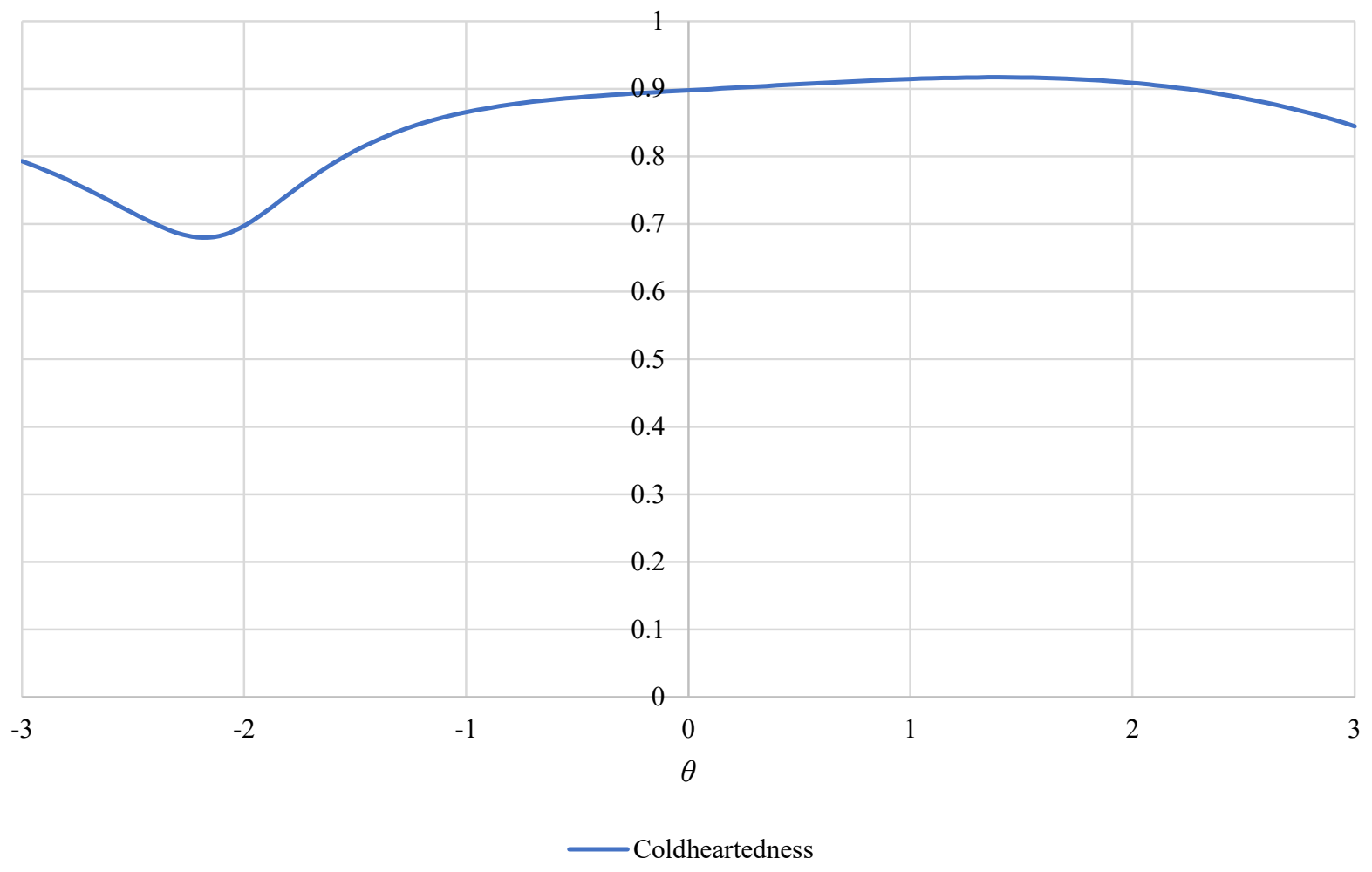

Supplemental Figure 10. Sample 1 test reliability function for PPI-R Coldheartedness scale estimated using GGUM. 
Test Reliability Functions for TriPM Scales

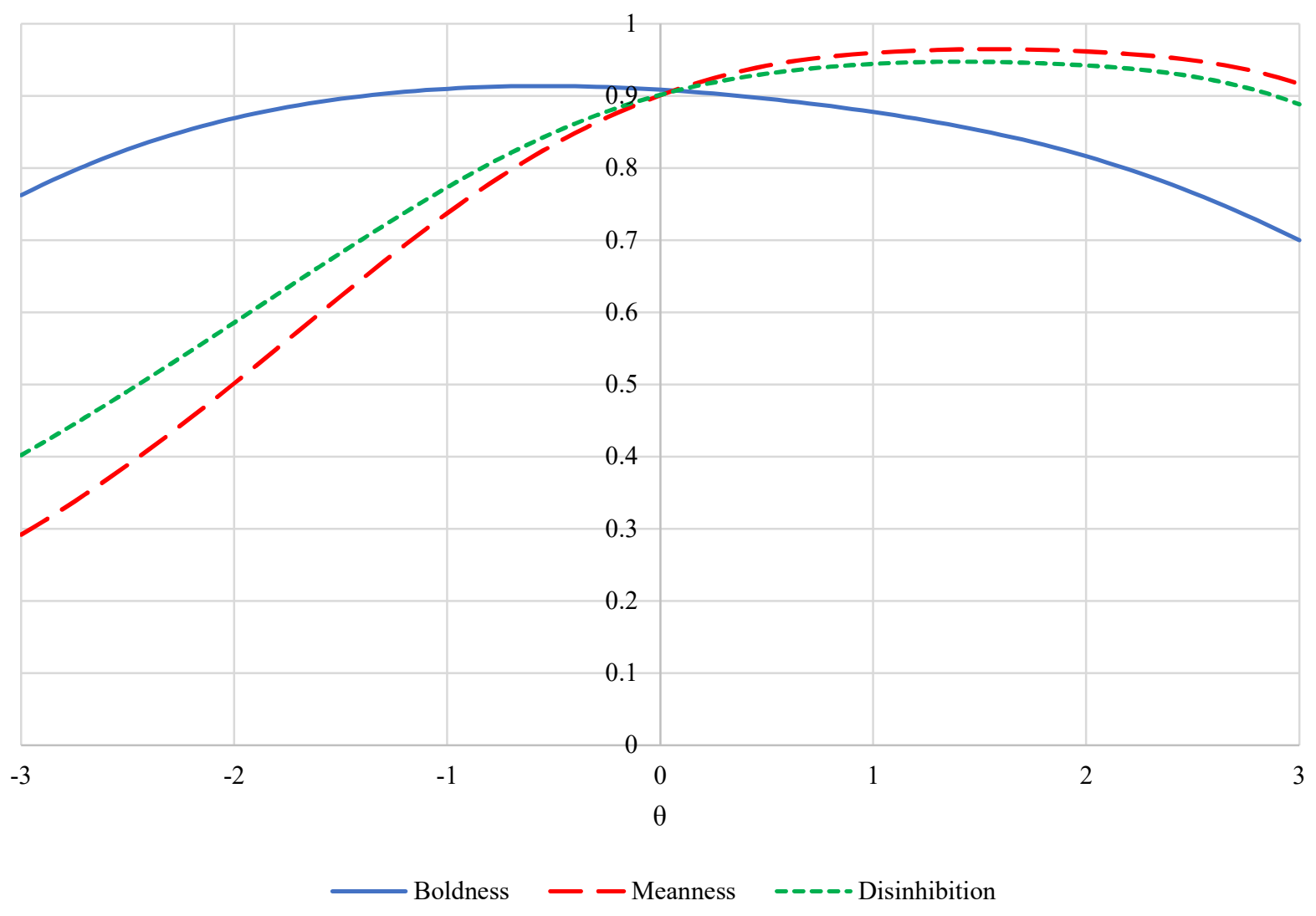

Supplemental Figure 11. Sample 2 test reliability functions for TriPM scales estimated using GPCM. 


\section{Supplemental Power Analysis}

Monte Carlo simulations were conducted to evaluate power for the present analyses. The results of the power analyses are presented in Table A1. Hypothetical personality trait levels were simulated for each of the two datasets from a normal distribution $(N=787, M=0, \mathrm{SD}=1$; and $N=603, M=0, \mathrm{SD}=1)$. The simulated predictor scores were then used to generate simulated outcomes of known distributions (i.e., Poisson, negative binomial) with known relations to the predictor variable.

Curvilinearity Simulations. To determine the generating parameters for the Poisson regression models, we utilized $b_{1}=.16$, as this corresponds to a 1-point increase in behavior counts in moving from the $-3^{\text {rd }}$ to $+3^{\text {rd }}$ standard deviation of the continuous, normally distributed predictor. For the quadratic term, we utilize the value of $b_{2}=.064$, as this value (in combination with the above linear term) results in a model that predicts an additional increase of roughly .75 when moving from the $-3^{\text {rd }}$ to $+3^{\text {rd }}$ standard deviation of the predictor. All simulated $b_{2}$ coefficients are positive as these power analyses were conducted with a directional hypothesis in mind. Blonigen (2013) hypothesized an increase in relationship at higher ends of the trait spectrum. As such, our ability to reliably detect positive curvilinearity was evaluated with these simulations. The quadratic model evaluated in is shown in Figure A1. These values were utilized because they were judged by the authors to constitute reasonably large effects that we would expect to be capable of detecting.

To explain how we derived the generating parameters for the negative binomial model, we must first explain the technical difference between the Poisson and negative binomial models. Mathematically, the Poisson model (assuming an intercept of 0 ) can be stated as:

$$
E(Y \mid X)=e^{\mathbf{b}(\mathbf{X})}
$$




\section{FEARLESS DOMINANCE AND CURVILINEARITY}

where $\mathbf{b}$ represents a matrix of regression weights and $\mathbf{X}$ represents a matrix of predictors corresponding to the elements of the $\mathbf{b}$ matrix. The negative binomial model is the same as the Poisson, with the addition of an overdispersion parameter, $\kappa$, to account for zero-inflation:

$$
E(Y \mid X)=e^{\mathbf{b}(\mathbf{X})+\kappa}
$$

Poisson model assumes that the variance of $Y$ is equal to $\mathbf{b}(\mathbf{X})^{*} \mu$, where $\mu$ is the mean of $Y$. Due to this relation, the weights used in Poisson models are $\mu / \mathbf{b}(\mathbf{X})$.

Due to the change in the base assumptions about variation in $Y$, the scale of the regression coefficients cannot be directly compared for these two models. In negative binomial models, the variation in $Y$ is assumed to be equal to $\mu(1+\kappa \mu)$. Thus, to determine appropriate values for the generating function we determined - for the largest dispersion parameter in our actual data - the mean of $Y$, and used the observed dispersion parameter to calculate the predicted variance of $Y$ by $\operatorname{Var}(Y)=\mu(1+\kappa \mu)$. Using this information, we calculated the ratio: $\operatorname{Var}(Y) / \mu$ for our actual data. Next, we examined the simulations for the Poisson model discussed above to find the mean of $Y$. Using the mean of $Y$ in our simulations, we found the values of $\operatorname{Var}(Y)$ that would result in the same ratio of $\operatorname{Var}(Y) / \mu$ as found in the real data. Upon finding the variance value that made these ratios equal, we then determined the appropriate value for the dispersion for the simulated data by:

$$
\kappa=\frac{\operatorname{Var}(Y)-\mu}{\mu^{2}}
$$

This procedure allowed us to determine appropriate values for the dispersion parameter in our simulation while maintaining the same regression coefficients used in the simulation for Poisson regression. For example, for antisocial behavior the mean was .90 , and its largest dispersion parameter in our analyses was 2.79 (see Table 2). Using this information, we 


\section{FEARLESS DOMINANCE AND CURVILINEARITY}

determined the expected variance to be 3.16 , yielding a variance to mean ratio of 3.51 . In our simulation of this sample for the Poisson regression we found a mean $Y$ value of 1.08 . The variance value that would make the ratios between real and simulated data equal was 3.79 . This means that a comparable dispersion parameter for our simulated data is $\kappa=2.33$.

Two separate distributions were used for evaluating power of the OLS regression solutions to account for violations of the normality assumption. This is particularly relevant for those regressions predicting proactive aggression theta scores, which had meaningful positive skew (see Figure A2). A standard normal distribution was utilized for modeling error in $Y$ for normally distributed outcomes. The exponential distribution with a rate $(\lambda)$ of 1 was identified as acceptable for modeling the error distribution in proactive aggression (see Figure A2). As $\mathrm{E}[X]=$ $(1 / \lambda), 1$ was subtracted from all error terms so the error distribution was centered on zero.

One thousand datasets were simulated for each model. Type 1 error was evaluated when simulated outcomes were regressed on the simulated personality trait predictors in models that included no curvilinear effect. Using a $\alpha$ cutoff of .05, roughly $5 \%$ of the time a statistically significant curvilinear effect $\left(b_{2}\right)$ was found when no curvilinearity was present (see Table A1), indicating that the nominal 5\% type 1 error rate could be expected in both samples used in the current study.

Power was evaluated using a significance cutoff corresponding to the nominal type 1 error rate. The cutoff was identified using the $95^{\text {th }}$ percentile of all quadratic $\left(b_{2}\right)$ coefficients. ${ }^{1}$ This cutoff represents the value above which only five percent of $b_{2}$ coefficients would fall given a null curvilinear effect. One thousand new datasets for each model were simulated with the

\footnotetext{
${ }^{1}$ This cutoff is necessary to hold type 1 error rate constant at 5\% while power was being evaluated. Also note that this assumes a directional hypothesis. As discussed, Blonigen's (2013) hypothesis suggests that there is positive curvilinearity.
} 


\section{FEARLESS DOMINANCE AND CURVILINEARITY}

addition a $b_{2}$ value of .064 . Power was determined by calculating the proportion of $b_{2}$ coefficients that fell above the $95 \%$ cutoff identified in the Type 1 error simulations.

As shown in Figure 1A, the curvilinear effect used is representative of the curvature implied by the Blonigen (2013) hypothesis. Figure 1A also shows that the curvature being evaluated is relatively modest, with a total predicted increase of roughly 2 counts in moving from the $-3^{\text {rd }}$ to $+3^{\text {rd }}$ standard deviation of the predictor.

A total of six power analyses were conducted to evaluate curvilinearity, a Poisson and negative binomial model for each sample size, as well as normal and skewed OLS models for Sample 2. Each of the two negative binomial models were simulated using the largest dispersion parameter identified within the relevant sample. In Sample 1, the estimated power of Poisson models was .83 and the estimated power of negative binomial models was .73. In Sample 2, the estimated power of Poisson models was .79 and the estimated power of negative binomial models was .60. Sample 2's power for OLS models were .72 and .65 for the normal and skewed distributions respectively. These simulations indicate that our analyses are sufficiently powered to detect relatively modest curvature in most instances.

Interaction Simulations. When simulating hypothetical personality trait levels for the interaction simulations, it was necessary to account for covariance between variables. Metaanalytic analyses were utilized to identify covariance parameters for the PPI-R (Miller \& Lynam, 2012) and TriPM ([redacted for review], in preparation). The covariance between FD and SCI was set to equal .048. The Boldness-Disinhibition, Boldness-Meanness, and MeannessDisinhibition, covariances were set to equal $-.065, .165$, and .527 respectively.

Generating parameters for the Poisson regression interaction models were selected to be representative of known linear relationships with the measured outcomes. In Sample 1, FD and 


\section{FEARLESS DOMINANCE AND CURVILINEARITY}

SCI were used to predict $\mathrm{CAB}$ substance abuse and $\mathrm{CAB}$ antisocial behavior. A meta-analytic review of the literature (Miller \& Lynam, 2012) identified correlations of .07 and .12 respectively between FD and those outcomes. As such, a modest positive linear effect $\left(b_{1}=.1\right)$ was selected to represent FD. The same review identified correlations between SCI and the CAB outcomes (substance abuse, antisocial behavior) as .26 and .36 respectively. A moderately sized linear regression coefficient $\left(b_{2}=.3\right)$ was selected to represent these effects. A meta-analytic review was also used to estimate the true linear effects between the TriPM and measured outcomes ([redacted for review], in preparation). Boldness has a modest positive relationship with externalizing behaviors (weighted $\mathrm{ES}=.103$ ). A representative linear regression coefficient was selected $\left(b_{1}=.1\right)$. Meanness (weighted $\left.\mathrm{ES}=.327\right)$ and disinhibition (weighted $\left.\mathrm{ES}=.396\right)$ revealed somewhat stronger associations with externalizing outcomes. As such, their linear coefficients were set at .33 , and .40 respectively. An interaction coefficient $\left(b_{3}\right)$ of .1 was selected as a modest, but reasonably detectable interaction effect. Dispersion parameters for the negative binomial models were identified using a method identical to that described within the curvilinearity simulations as were $Y$ error distributions for normal and skewed OLS regression simulations.

Power analyses for interaction effects were conducted in a manner consistent with the curvilinearity simulations. One thousand datasets were simulated for each model. Type 1 error was evaluated when simulated outcomes were regressed on the simulated personality trait predictors in models that included no interaction effect. Using a $\alpha$ cutoff of .05 , roughly $5 \%$ of the time a statistically significant interaction effect $\left(b_{3}\right)$ was found when no interaction was present (see Table A1), indicating that the nominal 5\% type 1 error rate could be expected in both samples used in the current study. Power was evaluated using a significance cutoff 


\section{FEARLESS DOMINANCE AND CURVILINEARITY}

corresponding to the nominal type 1 error rate. The cutoff was identified using the $95^{\text {th }}$ percentile of all interaction $\left(b_{3}\right)$ coefficients. One thousand new datasets for each model were simulated with the addition a $b_{3}$ value of .10 . Power was determined by calculating the proportion of $b_{3}$ coefficients that fell above the 95\% cutoff identified in the Type 1 error simulations.

A total of nine power analyses were conducted to evaluate the interaction models. A Poisson model for Sample 1 (as no negative binomial or OLS interaction models were indicated for the PPI-R variables), and eight Sample 2 simulations (a Poisson, Negative Binomial, and two OLS models to represent both the $\mathrm{B}^{*} \mathrm{D}$ and $\mathrm{B} * \mathrm{M}$ interaction effects). Again, each of the two negative binomial models were simulated using the largest dispersion parameter identified within the relevant sample. In Sample 1, the estimated power of the Poisson models was .92. In Sample 2, the estimated power of the Poisson models was .78 (B*D) and $.86\left(\mathrm{~B}^{*} \mathrm{M}\right)$, and the estimated power of the negative binomial models was .62 $\left(\mathrm{B}^{*} \mathrm{D}\right)$ and $.76\left(\mathrm{~B}^{*} \mathrm{M}\right)$. Our OLS regressions for normally distributed outcomes were shown to have a power of $.77\left(B^{*} \mathrm{D}\right)$ and $.80\left(\mathrm{~B}^{*} \mathrm{M}\right)$, while the power for positively skewed outcomes was identified as $.80\left(\mathrm{~B}^{*} \mathrm{D}\right)$ and $.77\left(\mathrm{~B}^{*} \mathrm{M}\right)$. As with the curvilinear effects, the simulations indicate that our analyses are sufficiently powered to detect relatively modest interactions in most instances. 
FEARLESS DOMINANCE AND CURVILINEARITY

\section{Table A1}

Curvilinearity Power Analysis

\begin{tabular}{|c|c|c|c|c|c|c|c|}
\hline \multirow[b]{2}{*}{ Curvilinear Models } & \multicolumn{5}{|c|}{ Model Parameters } & \multirow[b]{2}{*}{$\mathrm{T} 1 \mathrm{E}$} & \multirow[b]{2}{*}{ Power } \\
\hline & $\mathrm{N}$ & $\kappa$ & $b_{1}$ & $b_{2}$ & $b_{3}$ & & \\
\hline \multicolumn{8}{|l|}{ Sample 1} \\
\hline $\mathrm{P}$ & 787 & & .16 & .064 & & .06 & .83 \\
\hline $\mathrm{NB}_{1}$ & 787 & 4.10 & .16 & .064 & & .06 & .73 \\
\hline \multicolumn{8}{|l|}{ Sample 2} \\
\hline $\mathrm{P}$ & 596 & & .16 & .064 & & .05 & .79 \\
\hline $\mathrm{NB}_{2}$ & 596 & 2.33 & .16 & .064 & & .06 & .60 \\
\hline OLS (Normal) & 596 & & .16 & .064 & & .07 & .72 \\
\hline OLS (Skewed) & 596 & & .16 & .064 & & .07 & .65 \\
\hline \multirow{2}{*}{\multicolumn{8}{|c|}{$\begin{array}{l}\text { Interaction Models } \\
\text { Sample } 1\end{array}$}} \\
\hline & & & & & & & \\
\hline $\mathrm{P}$ & 787 & & .10 & .30 & .10 & .04 & .92 \\
\hline \multicolumn{8}{|l|}{ Sample 2} \\
\hline $\mathrm{P}_{\mathrm{B} * \mathrm{D}}$ & 596 & & .10 & .40 & .10 & .06 & .78 \\
\hline $\mathrm{P}_{\mathrm{B} * \mathrm{M}}$ & 596 & & .10 & .33 & .10 & .05 & .86 \\
\hline $\mathrm{NB}_{\mathrm{B} * \mathrm{D}}$ & 596 & 2.31 & .10 & .40 & .10 & .06 & .62 \\
\hline $\mathrm{NB}_{\mathrm{B} * \mathrm{M}}$ & 596 & 2.29 & .10 & .33 & .10 & .05 & .76 \\
\hline OLS $_{\mathrm{B} * \mathrm{D}}$ (Normal) & 596 & & .10 & .40 & .10 & .06 & .77 \\
\hline $\mathrm{OLS}_{\mathrm{B} * \mathrm{D}}(\mathrm{Skew})$ & 596 & & .10 & .40 & .10 & .06 & .80 \\
\hline OLS $_{B * M}$ (Normal) & 596 & & .10 & .33 & .10 & .06 & .80 \\
\hline $\mathrm{OLS}_{\mathrm{B} * \mathrm{M}}($ Skew $)$ & 596 & & .10 & .33 & .10 & .06 & .77 \\
\hline
\end{tabular}

Note. $\mathrm{NB}=$ Negative Binomial. $\mathrm{P}=$ Poisson. $\kappa=$ Dispersion. $\mathrm{T} 1 \mathrm{E}=$ Observed type 1 error rate. Identified dispersion parameter for $\mathrm{NB}_{1}$ corresponds to observed dispersion of 4.95 in Sample 1. Identified dispersion parameter for $\mathrm{NB}_{2}$ corresponds to observed dispersion of 2.79 in Sample 2. Simulated dispersion parameters were calculated using Formula A3. 
FEARLESS DOMINANCE AND CURVILINEARITY

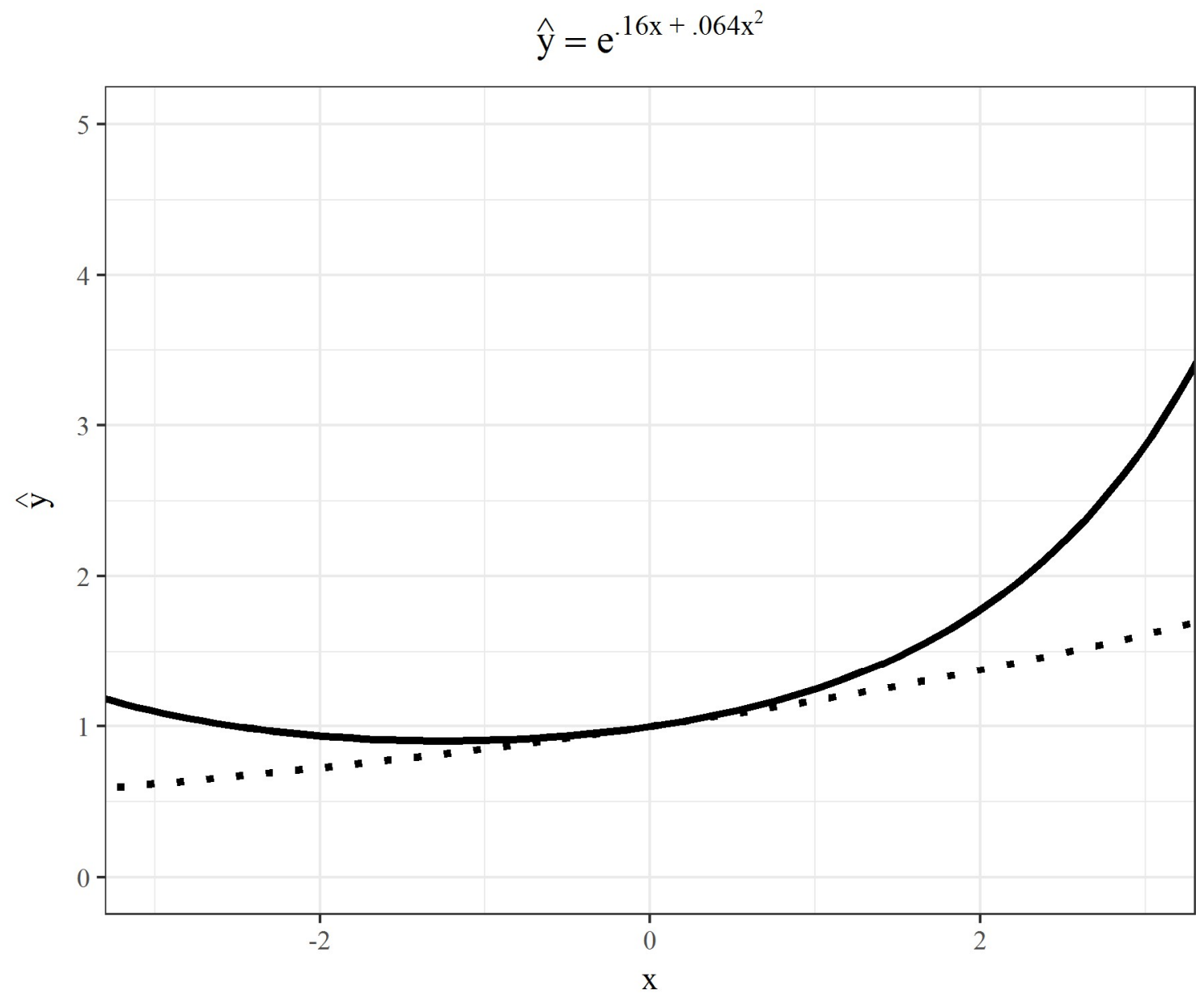

Figure A1. Depiction of the curvilinear effect being evaluated in power analysis. Dashed line indicates the same linear effect with no quadratic parameter. 


\section{Empirical and Theoretical Density Distributions}

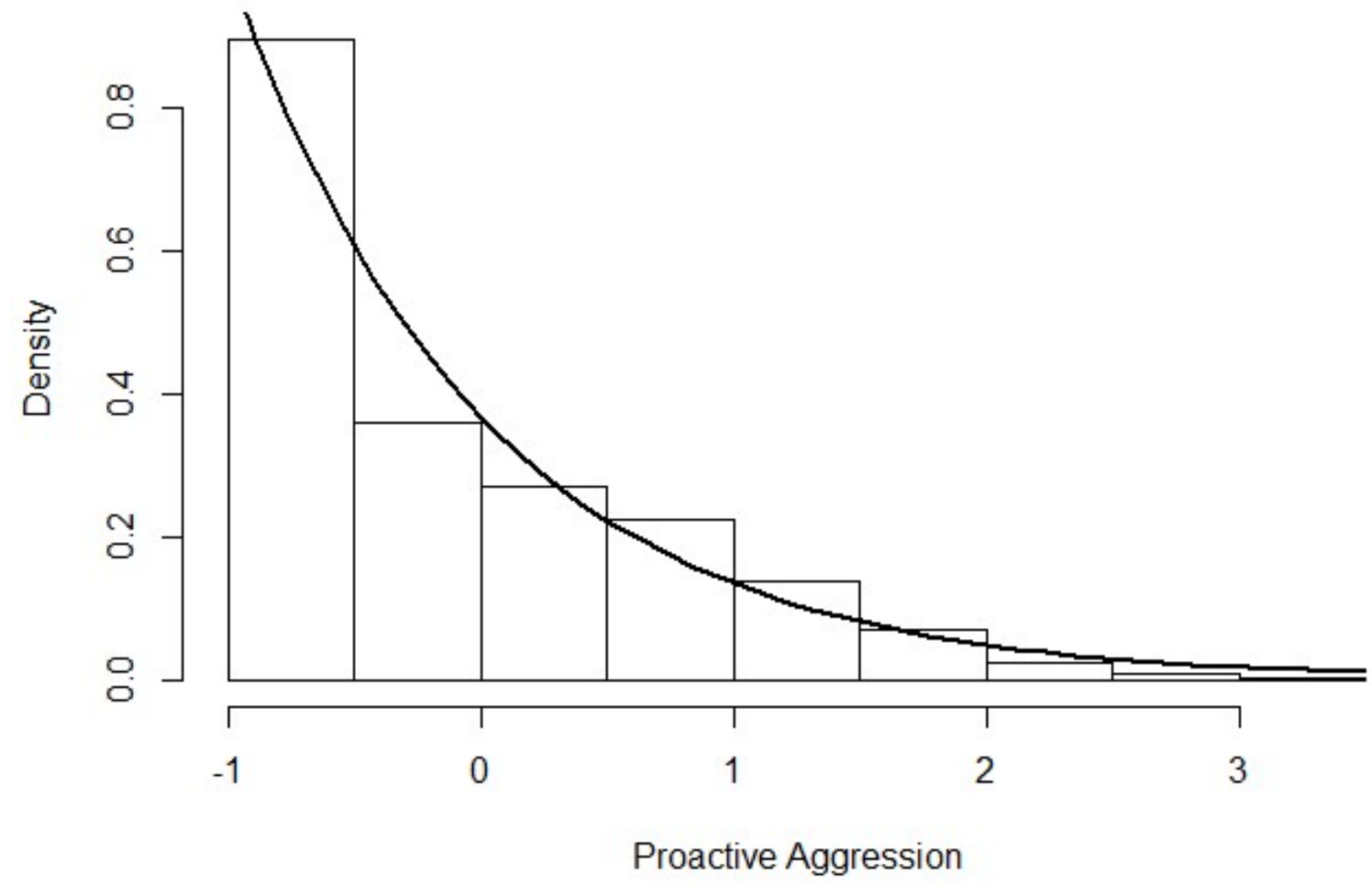

Figure A2. Observed density distribution of Proactive Aggression $\theta$ values. Solid line indicates the exponential distribution of the density function for $X+1$. Simulated error values were backtransformed allowing for $M=0$. 